\title{
The accuracy of emergency weight estimation systems in children-a systematic review and meta-analysis
}

\author{
Mike Wells $s^{1,2^{*}} \mathbb{D}$, Lara Nicole Goldstein ${ }^{1}$ and Alison Bentley ${ }^{1}$
}

\begin{abstract}
The safe and effective administration of fluids and medications during the management of medical emergencies in children depends on an appropriately determined dose, based on body weight. Weight can often not be measured in these circumstances and a convenient, quick and accurate method of weight estimation is required. Most methods in current use are not accurate enough, but the newer length-based, habitus-modified (two-dimensional) systems have shown significantly higher accuracy. This meta-analysis evaluated the accuracy of weight estimation systems in children. Articles were screened for inclusion into two study arms: to determine an appropriate accuracy target for weight estimation systems; and to evaluate the accuracy of existing systems using standard meta-analysis techniques. There was no evidence found to support any specific goal of accuracy. Based on the findings of this study, a proposed minimum accuracy of $70 \%$ of estimations within 10\% of actual weight (PW10 > 70\%), and $95 \%$ within $20 \%$ of actual weight (PW20 > 95\%) should be demonstrated by a weight estimation system before being considered to be accurate. In the meta-analysis, the two-dimensional systems performed best. The Mercy method (PW10 70.9\%, PW20 95.3\%), the PAWPER tape (PW10 78.0\%, PW20 96.6\%) and parental estimates (PW10 69.8\%, PW20 87.1\%) were the most accurate systems investigated, with the Broselow tape (PW10 55.6\%, PW20 81.2\%) achieving a lesser accuracy. Age-based estimates achieved a very low accuracy. Age- and length-based systems had a substantial difference in over- and underestimation of weight in high-income and low- and middle-income populations. A benchmark for minimum accuracy is recommended for weight estimation studies and a PW10 > 70\% with PW20 > 95\% is suggested. The Mercy method, the PAWPER tape and parental estimates were the most accurate weight estimation systems followed by length-based and age-based systems. The use of age-based formulas should be abandoned because of their poor accuracy.
\end{abstract}

Keywords: Weight estimation, Broselow tape, PAWPER tape, Mercy method

\section{Introduction}

It cannot be considered to be good medical practice to use a weight estimation system that is known to be inaccurate [1]. When children's weight cannot be measured during emergency care, an accurate, rapid estimation of weight is needed, as the safety and effectiveness of emergent interventions may ultimately depend on the accuracy of the weight estimation [2,3]. Since most drug doses in children are based on weight, an accurate estimation of weight is important to ensure that a correct amount of medication is administered to achieve

\footnotetext{
* Correspondence: mike.wells@emergencymedicine.co.za

'Division of Emergency Medicine, Faculty of Health Sciences, University of the Witwatersrand, 7 York Road, Parktown, Johannesburg 2193, South Africa ${ }^{2}$ Postnet Suite 429, Private Bag X1510, Glenvista 2058, South Africa
}

the desired effect, as well as to prevent the potential complications and side-effects of overdosing $[4,5]$. This is relevant because most paediatric medication errors occur in the Emergency Department and most cases of resultant patient harm are related to incorrect dosing [6-8].

The problem is that most contemporary methods used to estimate children's weight have been shown to lack sufficient accuracy and consistency of performance in different populations [9]. Most existing weight estimation systems are "one-dimensional", because a single variable, usually age or length, is used in the weight estimation methodology. These systems fail because a single variable cannot adequately account for the biological variability of weight-for-age and weight-for-length 
$[10,11]$. There is a wide variability of body habitus that is not accounted for in these weight-estimation systems, aggravated by the increasing levels of obesity affecting children [12, 13]. Newer, more promising, methods are the "two-dimensional" or dual length- and habitus-based systems, which include two variables in the estimation methodology: length (or a surrogate such as humerus or ulna length) and habitus (or a surrogate such as midarm circumference or waist circumference) [5, 14-17]. These have been shown to be much more accurate than the older, one-dimensional systems, in many studies [5, 15, 18-22].

Healthcare providers may also need more than one approach to emergency weight estimation: while parental estimates of weight can be very accurate, parents may not be present at the time that emergency care is required (especially in the prehospital environment) [9]. In these situations, an evidence-based alternative system may be required.

There has been a large amount of material published on weight estimation in children. It would be useful to combine the data from these studies to establish the accuracy of different methodologies both within and between different populations. Since many of the same weight estimation systems are used in populations with very different prevalences of underweight and obese children, it needs to be ascertained whether this impacts on the accuracy outcomes of these systems.

In order to create an evidence-based approach to emergency paediatric weight estimation, it is crucial to discover which methods predict weight most accurately and which are most appropriate for emergency use. This will enable clinicians to decide which systems they should incorporate into their clinical practice and will provide some guidance to those who administer, teach and train paediatric advanced life support on which systems are important.

The overall aim of this study was to determine which paediatric weight estimation systems most accurately estimate total body weight in children. The first objective was to determine whether there was evidence in the literature for an acceptable benchmark level of accuracy for a weight estimation system. The second objective was to extract and pool data on the performance of paediatric weight estimation systems to integrate the findings, provide a more comprehensive analysis on their functioning and identify those systems that operated best in diverse populations. The third objective was to directly compare the accuracy of paediatric weight estimation systems, for which paired data was available, using pooled data and meta-analysis techniques.

Only one meta-analysis has addressed this topic, but was limited to studies in low- and middle-income countries [23].

\section{Methods}

This systematic review and meta-analysis followed the PRISMA guidelines.

\section{Search strategy}

Online databases (MEDLINE, SCOPUS, Science Direct and Google) were interrogated for eligible studies, published between January 1983 and May 2017, using the following search terms: "paediatric weight estimation", "weight estimation children" and "Broselow tape". Citation lists of reviewed papers were examined for additional relevant articles. Studies in any language were included if English translations were obtainable. To minimise publication bias, all studies with adequate reporting were included, whether full-text articles, dissertations, abstracts, conference presentations or other unpublished data that had undergone some form of peer-review.

\section{Study selection and eligibility criteria}

All studies that evaluated weight-estimation methodologies were assessed for inclusion into the study by two separate investigators (MW and LG). Articles that contained discussions on desired targets of accuracy of weight estimation systems, or analysis of the performance of weight-estimation systems were included in the qualitative arm of the review. Studies that presented original data with either accuracy data (percentage of estimations within $10 \%$ of actual weight (PW10)) or bias and precision data (mean percentage error plus an appropriate indicator of variance), or both, were included in the meta-analysis. Studies that did not include original data, those that did not include usable data and those at high risk of bias (see below) were excluded from the meta-analysis (see Fig. 1).

\section{Data abstraction and analysis}

Data was extracted from the included studies independently by two researchers (MW, LG), cross-checked and confirmed. Standard statistics for meta-analysis of method-comparison studies were used [24], with an emphasis on evaluating accuracy (percentage of estimations within $10 \%$ of actual weight), bias (mean percentage error) as well as precision (limits of agreement of percentage error). Two methods of representing the pooled parametric and non-parametric data were employed: a fixed effects model weighted by inverse variance and a random effects model. In general, the random effects model was preferred because of the large variance within and between samples as well as the effects of several very large database studies that may have introduced bias. 


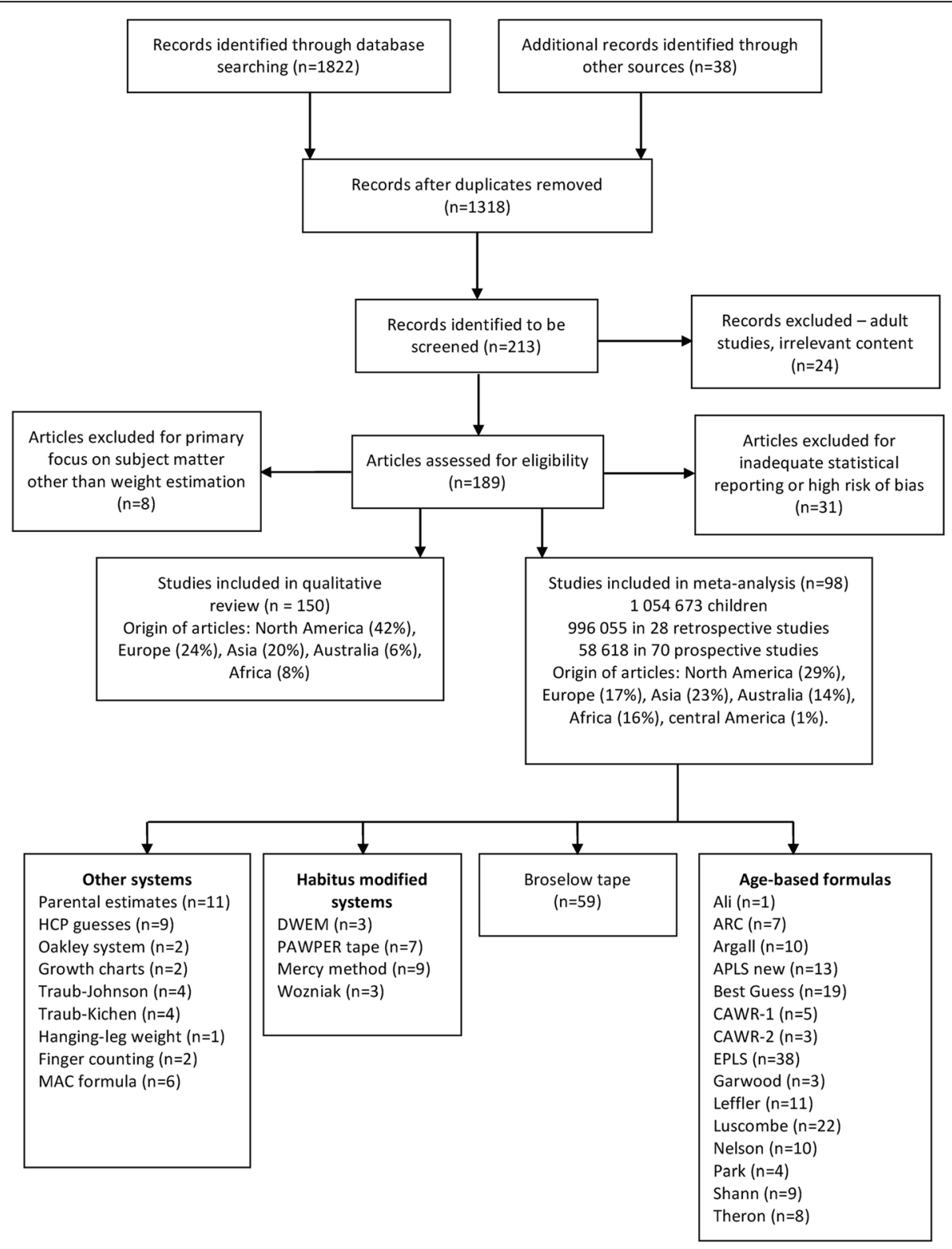

Fig. 1 The PRISMA flow-chart of the study design

Many of the evaluated studies presented incomplete data. Where it was possible, without risking bias, missing data was imputed using standard methodologies [25].

Direct comparisons between weight estimation systems, using pooled paired data, were performed with non-parametric techniques based on PW10 accuracy data, where such data was available.

\section{Subgroup analysis}

There was considerable heterogeneity in the use and composition of subgroups within the included studies. Wherever possible, subgroup analyses that had been performed in each study were included in the overall meta- analysis. The included subgroups focused on different age groups as previous studies have shown a difference in weight estimation accuracy between infants $(<1$ year), toddlers and pre-school children ( 1 to 6 years) and older children ( $>6$ years of age) [26].

\section{Risk of bias within and across studies}

Reporting bias was minimised by including all available methodologically sound studies (published or not). Methodological causes of potential bias were common (e.g. the Broselow tape was not actually used in many studies, but weight-estimates were generated from length data), but these were individually assessed and 
rated according to the level of risk of systematic bias. Studies with a high risk of bias were excluded from the meta-analysis (e.g. studies which excluded children above or below certain weight-for-length centiles).

\section{Sensitivity analysis}

There were three large database studies among those evaluated, with more than 100,000 children, one of which had more than 400,000 data points [27-29]. The effects of these "virtual" weight estimation studies, from very large databases, were carefully considered to establish any significant contribution to bias or distorted outcomes.

\section{Software}

Statistical analysis was performed using Stata (StataCorp. 2015. Stata Statistical Software: Release 14. College Station, TX: StataCorp LP), Graphpad Prism (GraphPad Prism version 8.00 for Mac, GraphPad Software, La Jolla, California, USA, www.graphpad.com) and Review manager (Review Manager (RevMan) [Computer program]. Version 5.3. Copenhagen: The Nordic Cochrane Centre, The Cochrane Collaboration, 2014).

\section{Results}

\section{Excluded studies}

The most common reason for exclusion of potentially relevant studies was incomplete data presentation (see Fig. 1). The large database studies did not have a significant impact on overall outcomes based on the sensitivity analysis and were therefore not excluded from the analysis.

\section{Characteristics of included studies}

Two-thirds of included studies evaluated multiple weight-estimation systems and contained paired data or made direct comparisons, while one-third evaluated only a single system. Prospective studies accounted for the majority of articles (70/98 (71.4\%)) but a minority of total patients $(58,618 / 1,054,673(5.6 \%))$.

Table 1 provides a descriptive summary of the studies included in both the qualitative review as well as the meta-analysis, including the major findings and limitations of each study and the risk of bias assessment for each included study.

\section{Benchmark accuracy for a weight estimation system}

After studying the 150 identified articles, only three articles were found to propose a statistically meaningful target for a weight estimation system: one article recommended that $95 \%$ of weight estimates must fall within $20 \%$ of actual weight and two articles suggested that $70 \%$ of estimates must be within $10 \%$ of actual weight and $95 \%$ of weight estimates must fall within
$20 \%$ of actual weight [11,30,31]. There was, however, no evidence found upon which to base any specific measurement analysis metric for a weight estimation system. There was also no credible evidence found of a tolerable weight estimation error, in terms of safety for drug dose calculation, for an individual child.

In 90/150 articles (60.0\%), there was no mention at all of an appropriate target for weight estimation accuracy. In $41 / 150$ articles $(27.3 \%)$ an error of $<10 \%$ was suggested as appropriate; in 11/150 articles $(7.3 \%)$ an error of $<20 \%$ was advocated; in $2 / 150$ articles $(1.3 \%)$ an error of $<30 \%$; and in $6 / 150$ articles $(4.0 \%)$ another value or a statistically inappropriate measure was proposed. None of the studies included any evidence to support these target figures. The values were selected based on clinical significance, pragmatic limits based on generalised therapeutic ratios, or based on guidelines on determining drug bioequivalence [32,33].

\section{Meta-analysis data on bias (trueness), precision and accuracy of paediatric weight estimation systems}

Table 2 contains a description of each of the weight estimation systems reviewed, as well as any restrictions on their use. The raw data and outcomes for each of the weight-estimation methodologies included in the metaanalysis are shown in Additional file 1: Table S1. From the individual study data, it could be seen that there was very poor within-study precision for most weight estimation systems (shown by the wide limits of agreement), with the exception of the two-dimensional methods, which generally had precision limits of agreement of less than $\pm 20 \%$.

Figure 2 shows the pooled data of the bias and precision for the weight-estimation systems evaluated. The fixed effects outcomes and data for the weight estimation methods not presented in Fig. 2 can be found in Table 3. The important findings can be summarised as follows:

- There was a wide variation in the weight estimation bias between low- and middle-income countries (overestimation) and high-income countries (underestimation). This was most noticeable with the agebased systems, less so with the length-based systems and least with the two-dimensional systems, which had virtually zero bias.

- There were very wide limits of agreement for all methods other than the PAWPER tape and the Mercy method.

Figure 3 show the overall accuracy data for each weight estimation system (PW10 data). Age-based systems were least accurate, length-based systems were slightly more accurate and parental estimates and the 


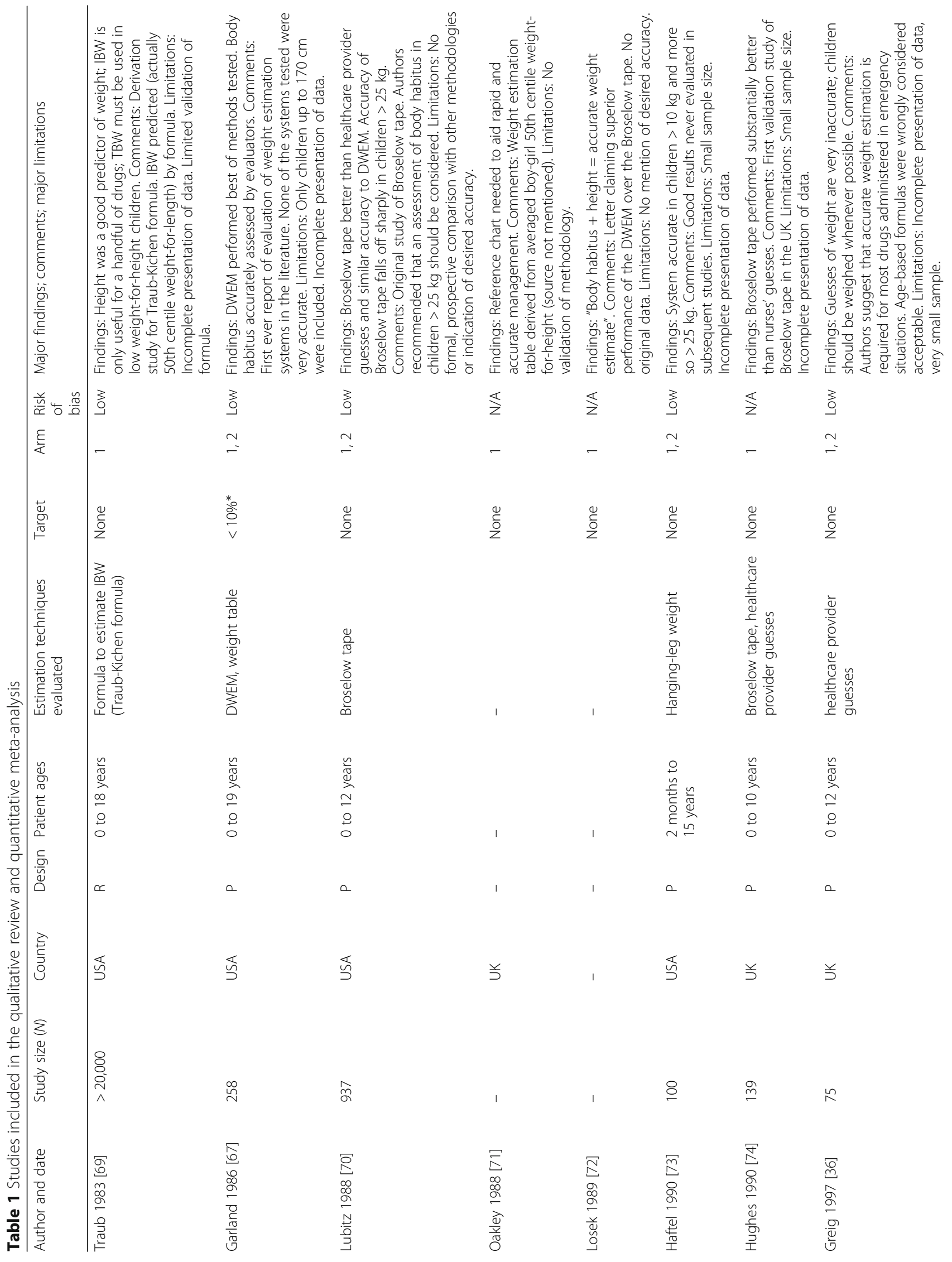




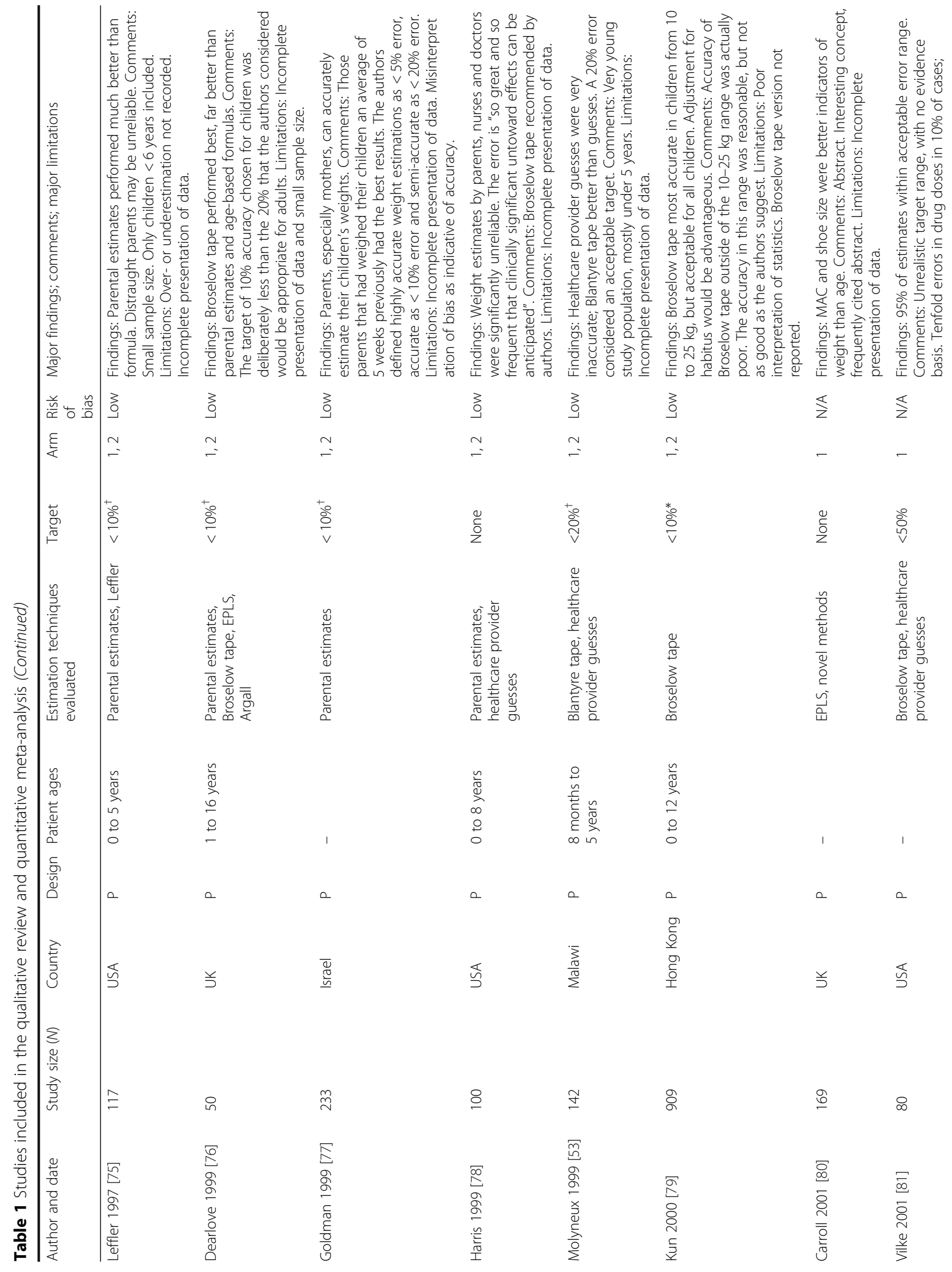




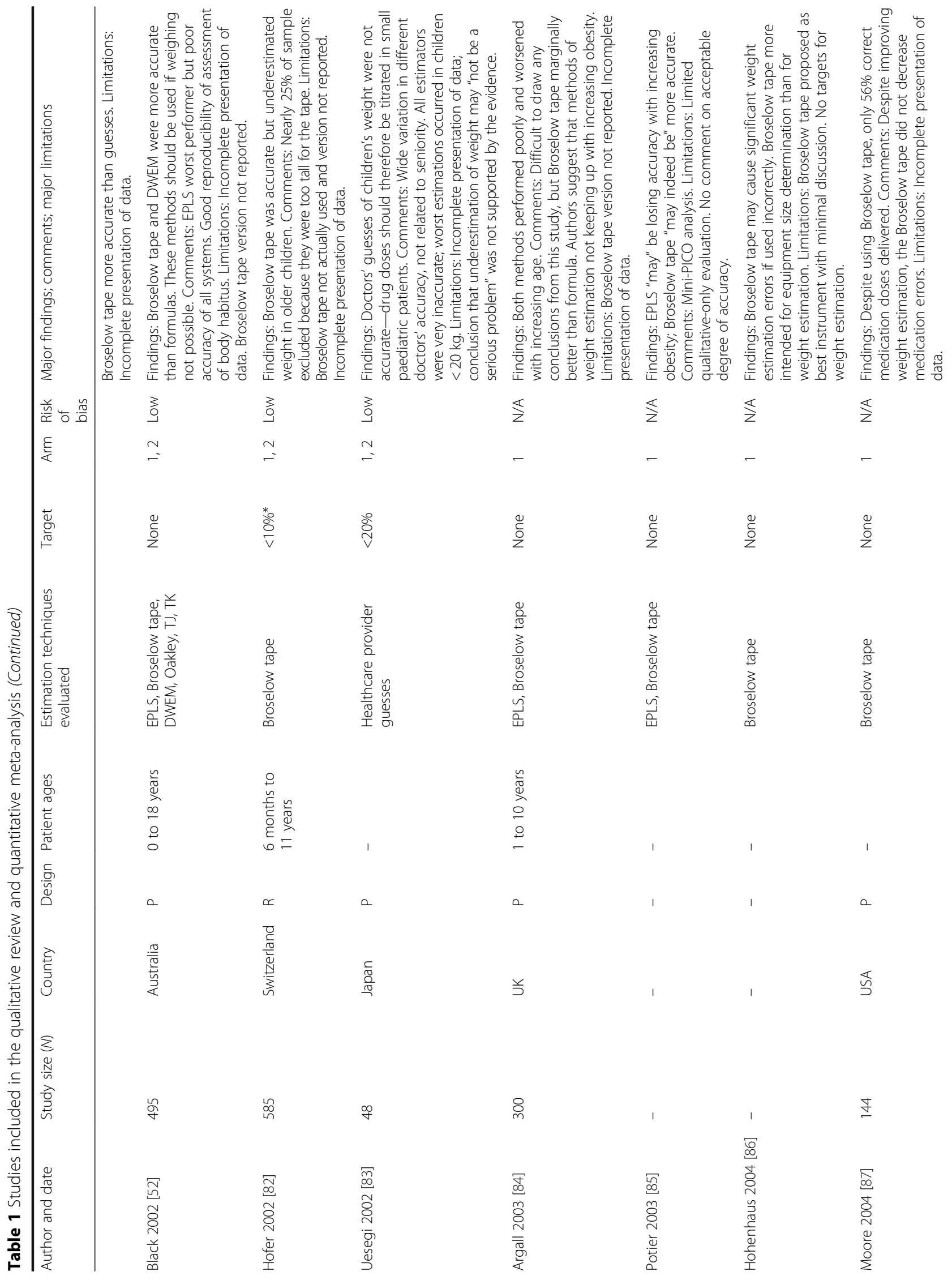




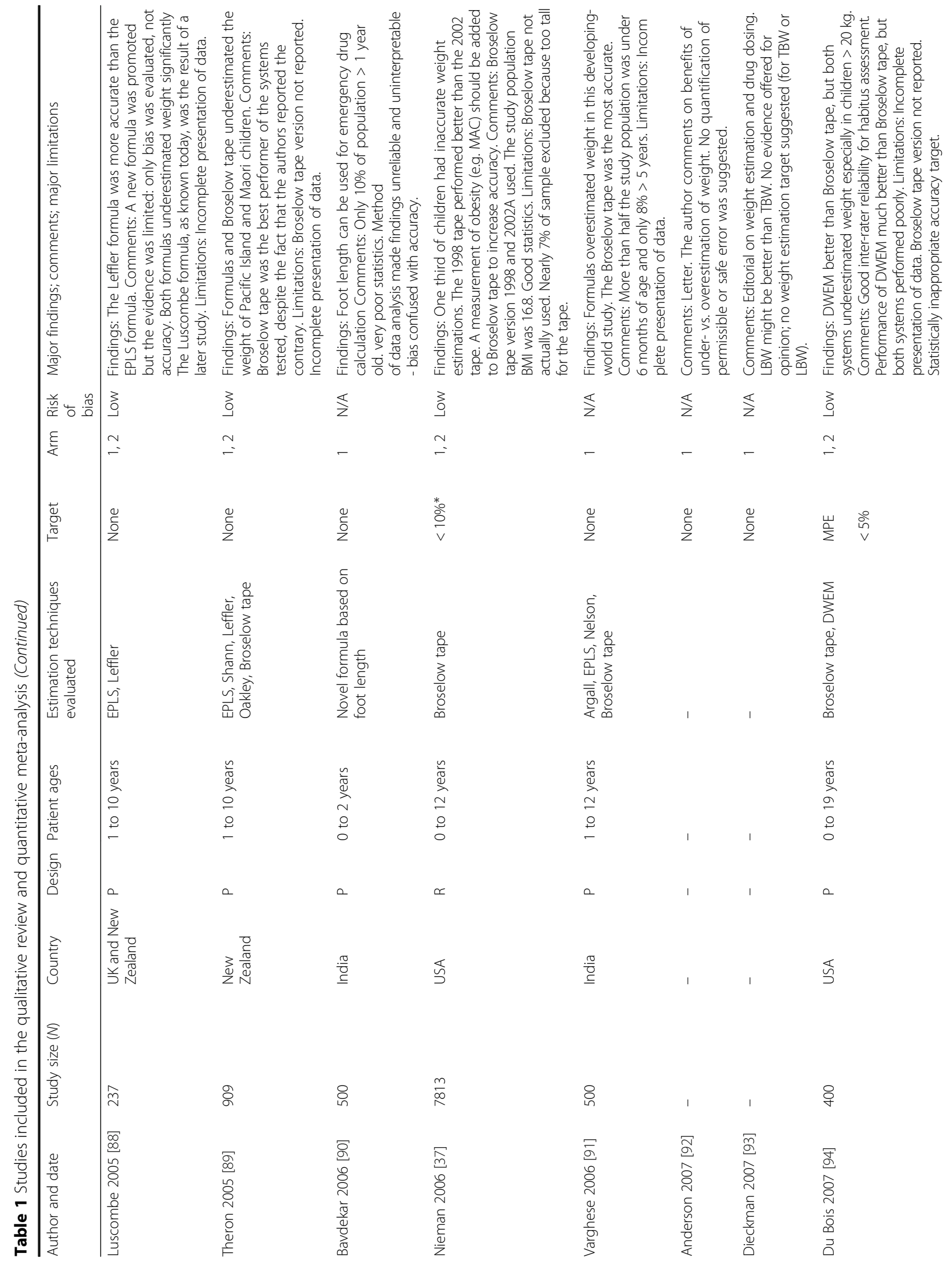




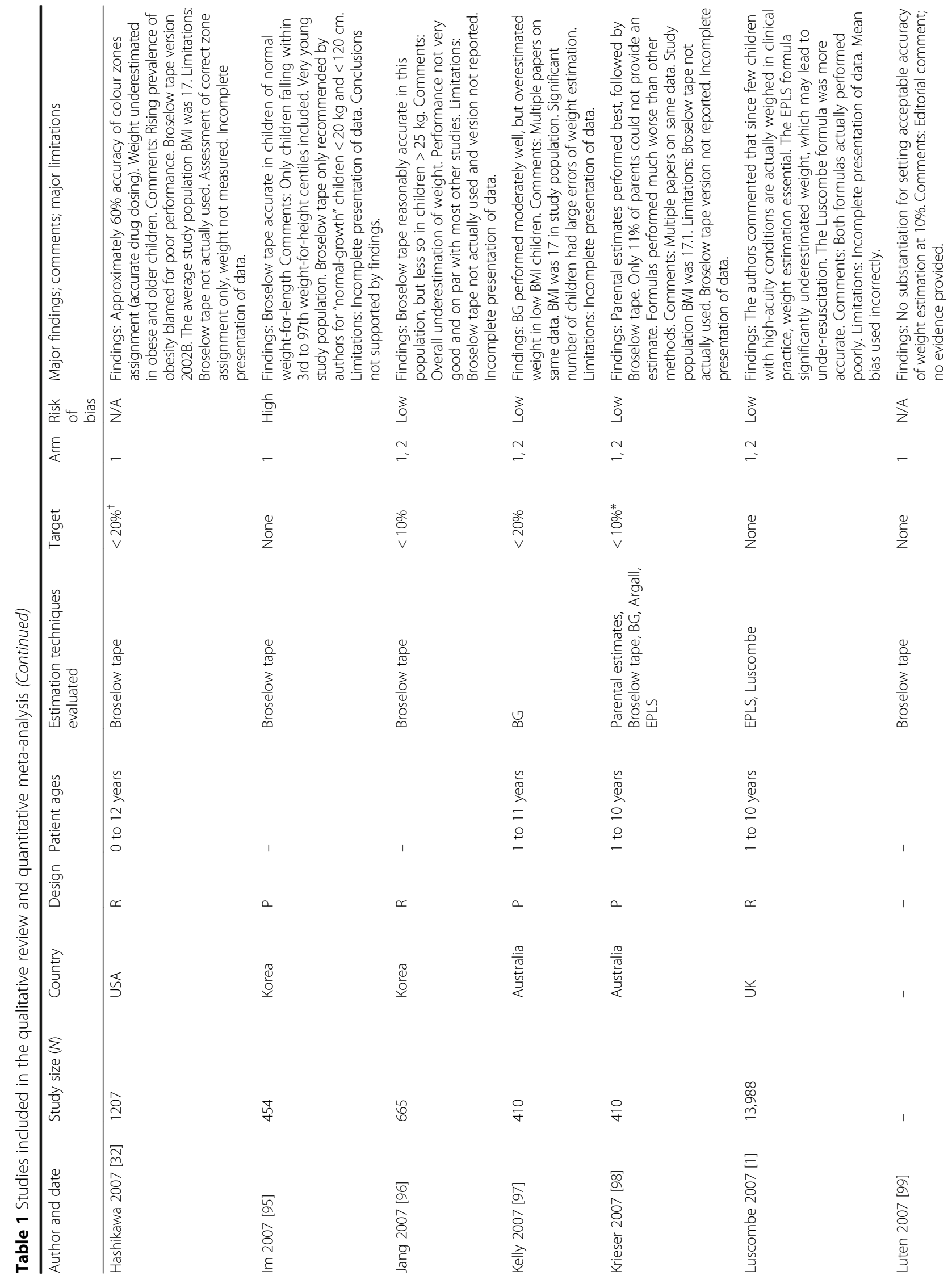




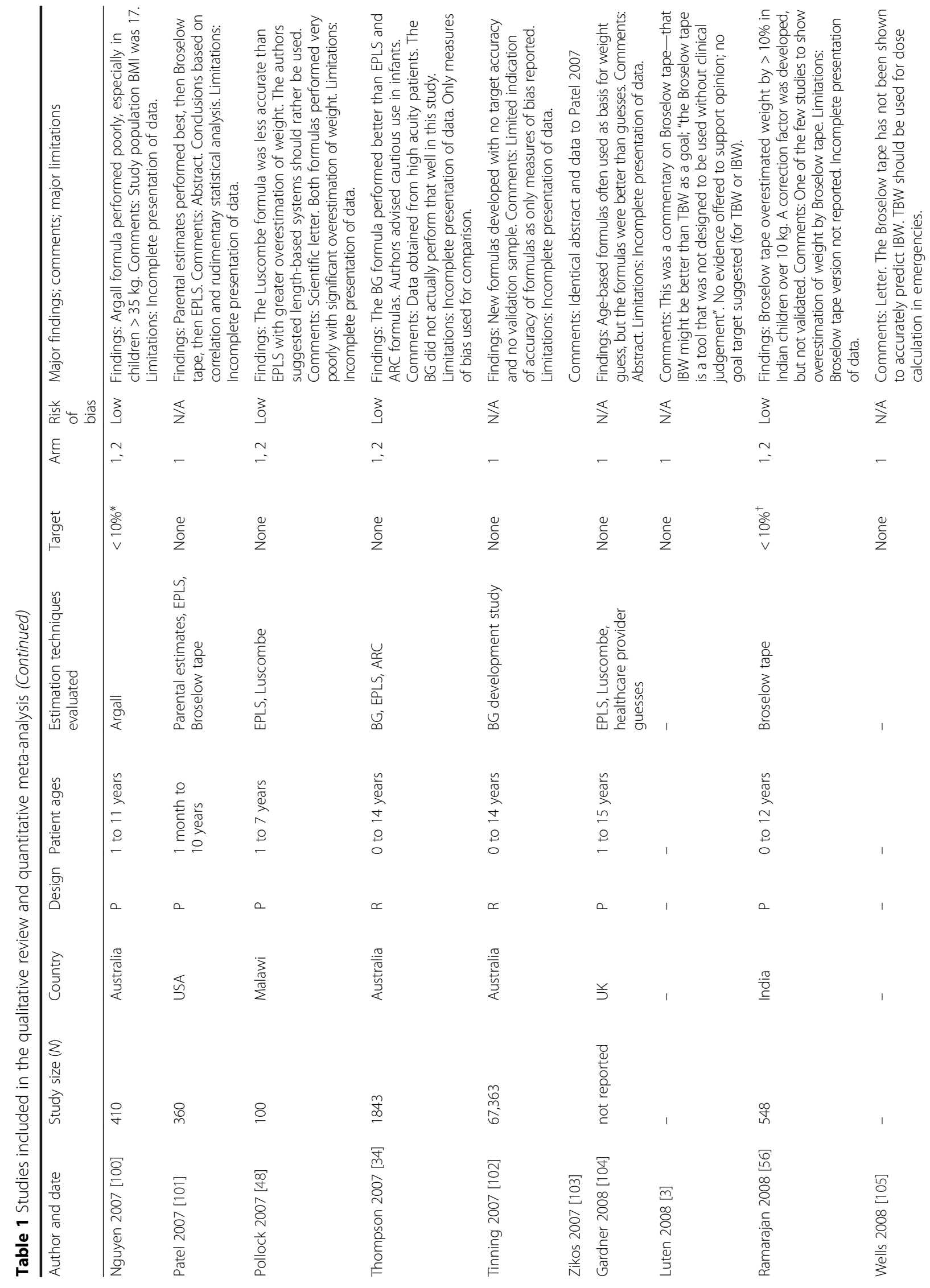




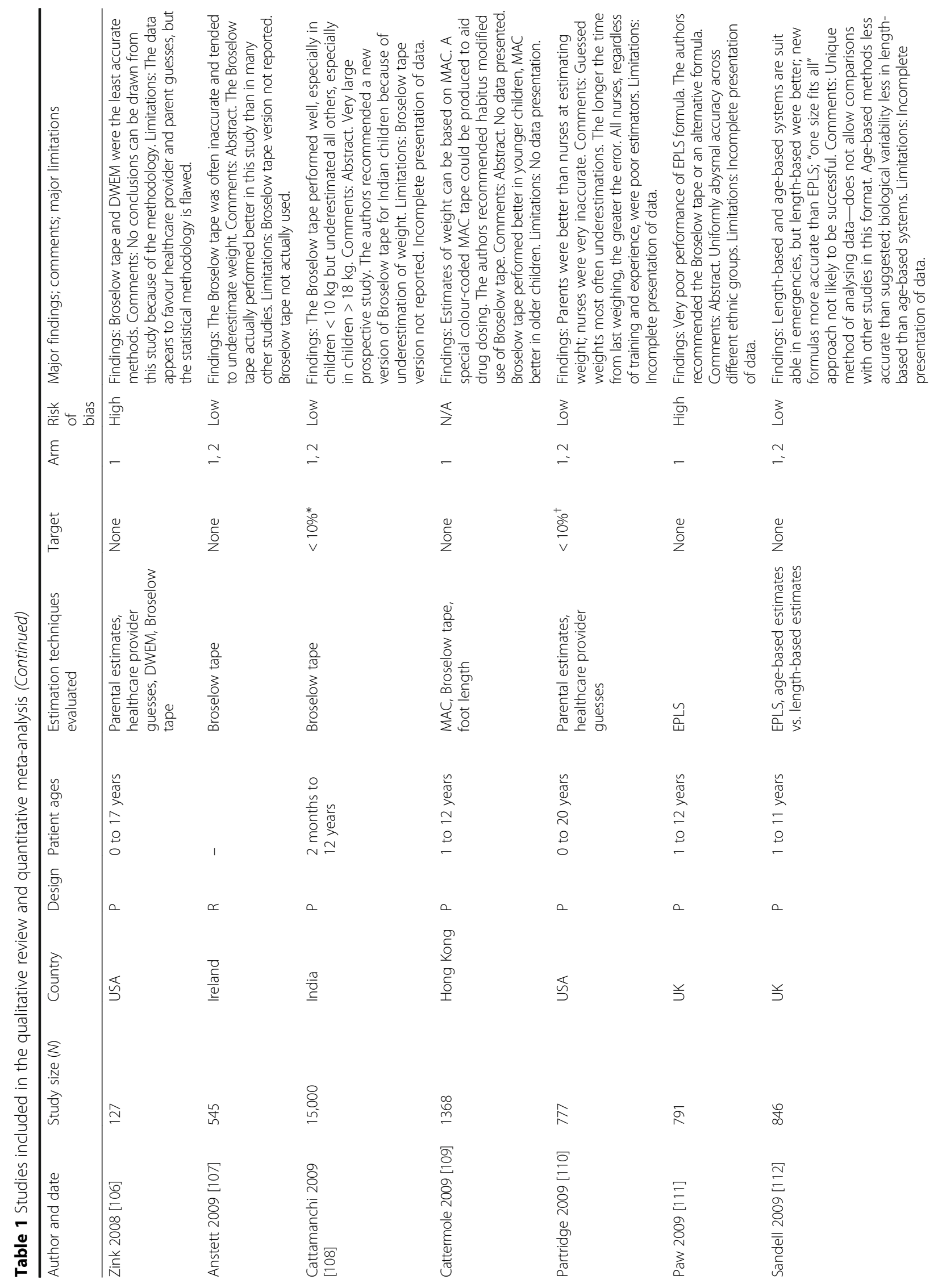




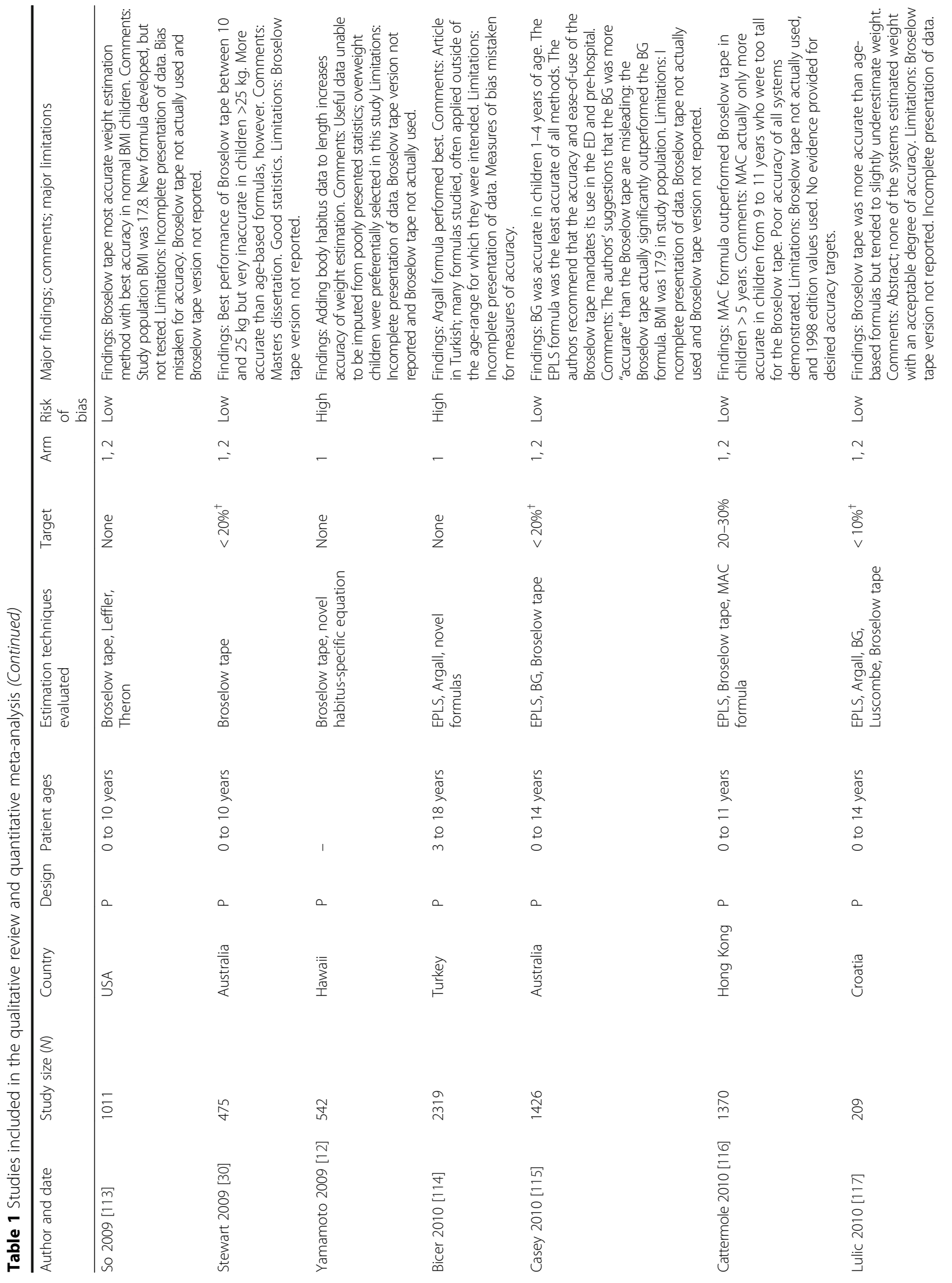


Wells et al. International Journal of Emergency Medicine (2017) 10:29

Page 13 of 43

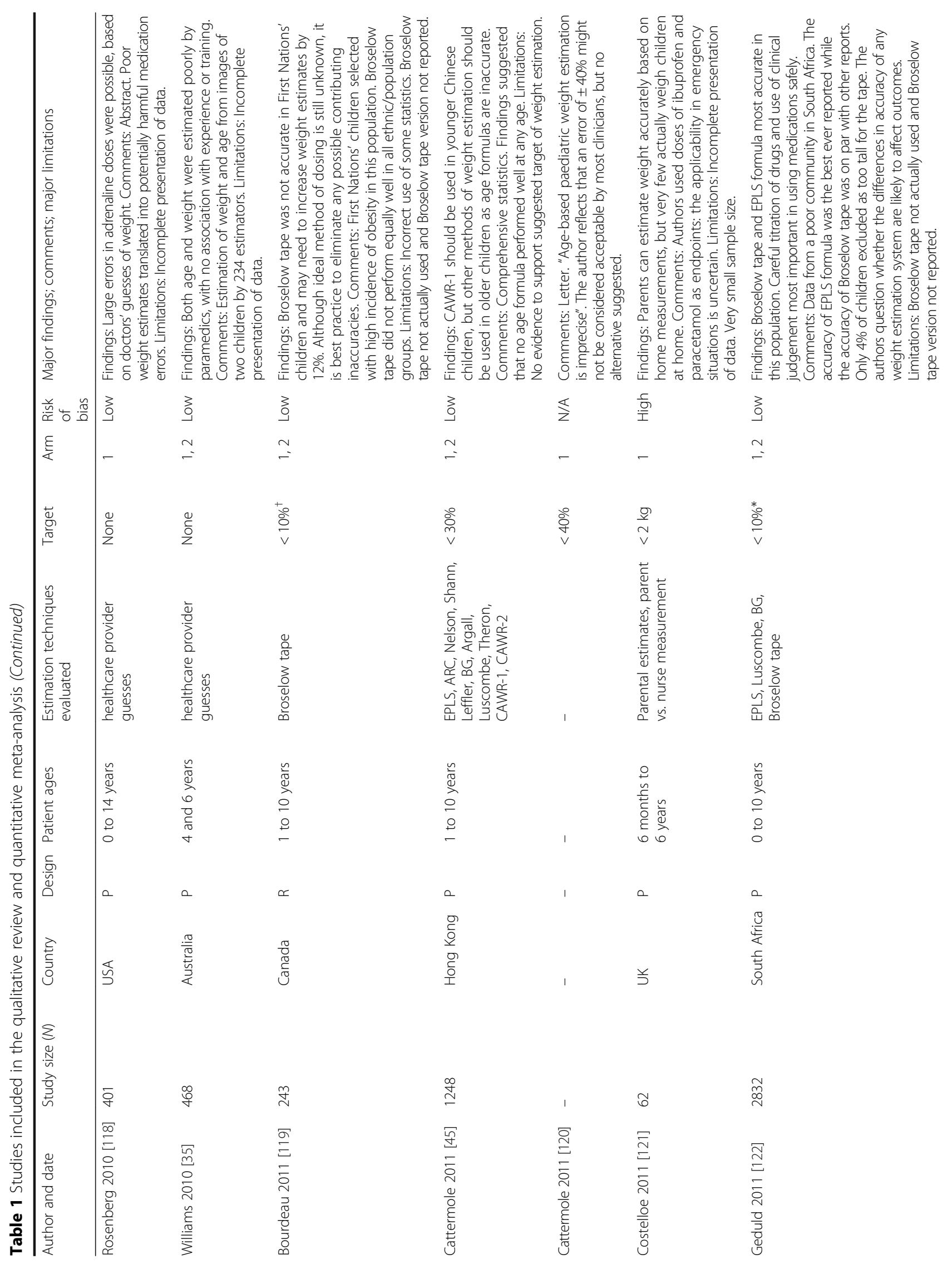




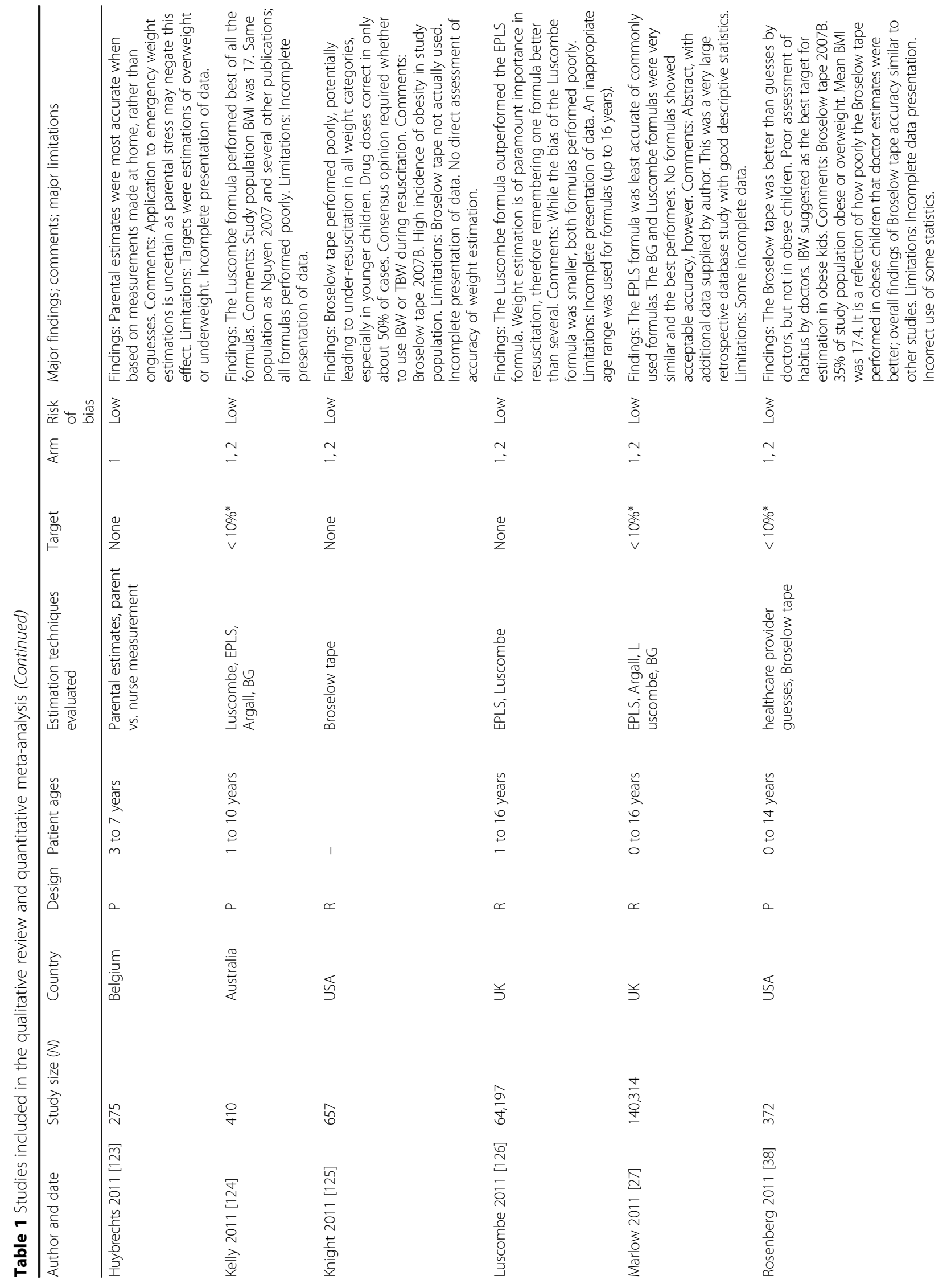


Wells et al. International Journal of Emergency Medicine (2017) 10:29

Page 15 of 43

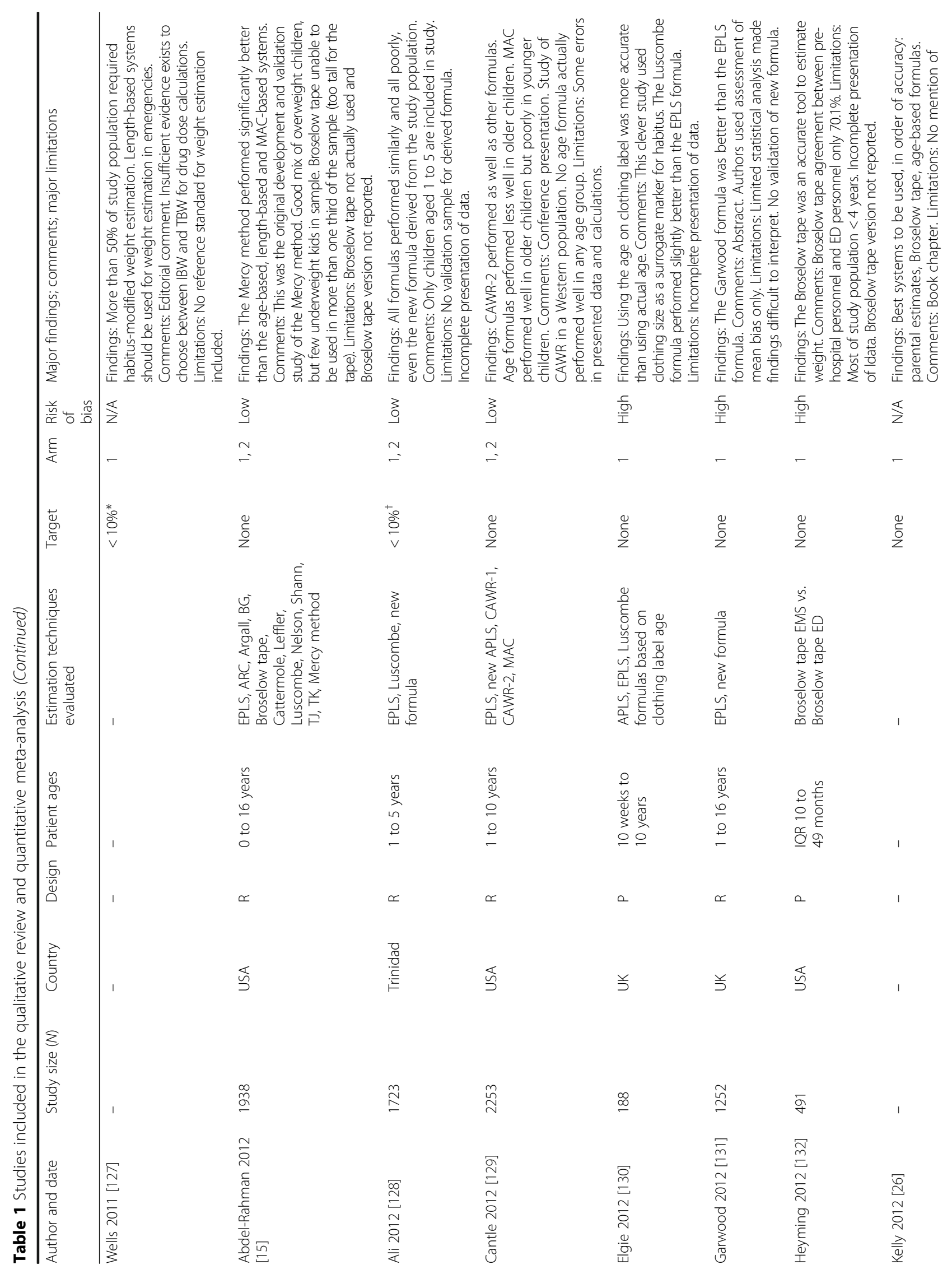




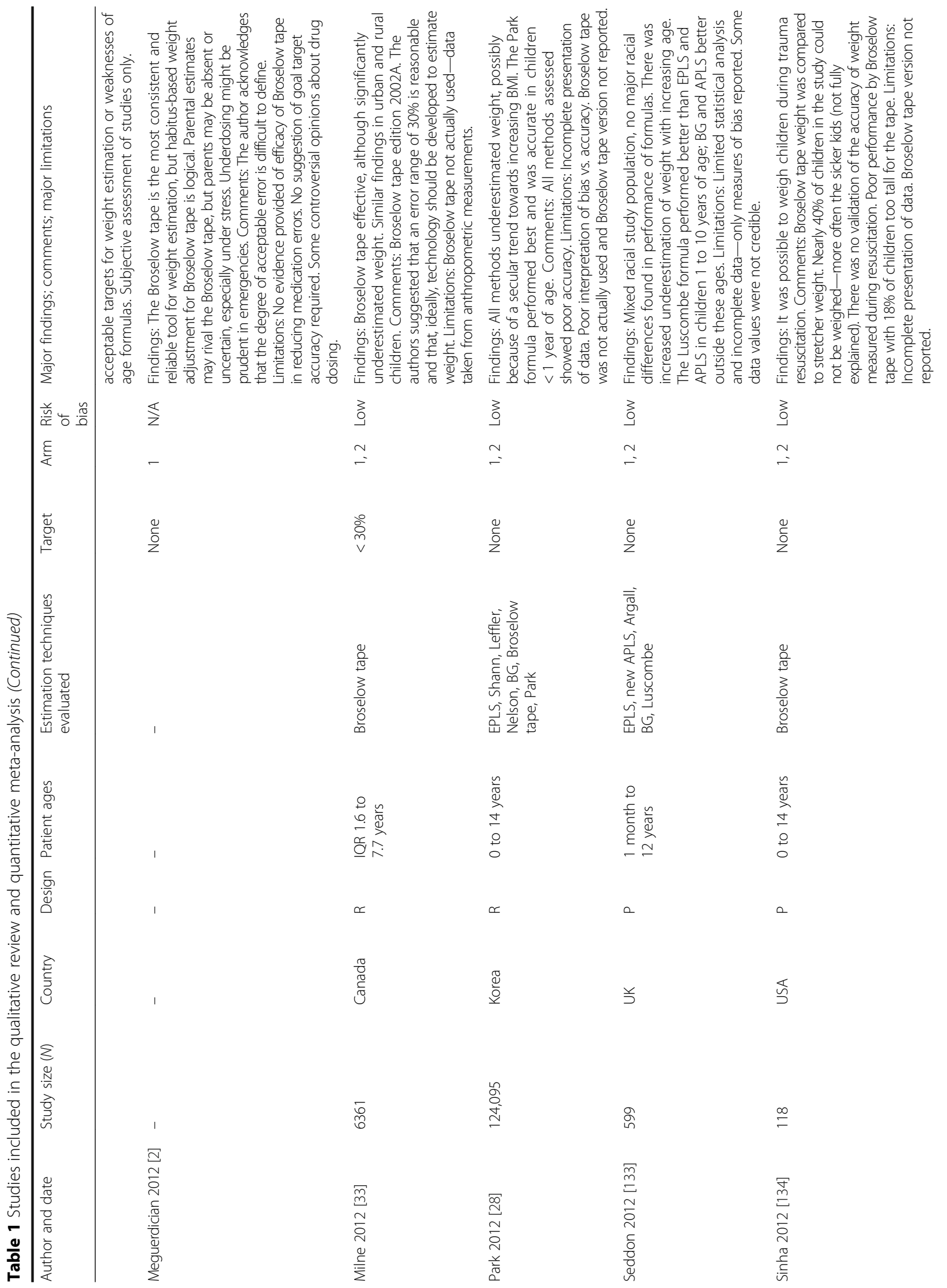




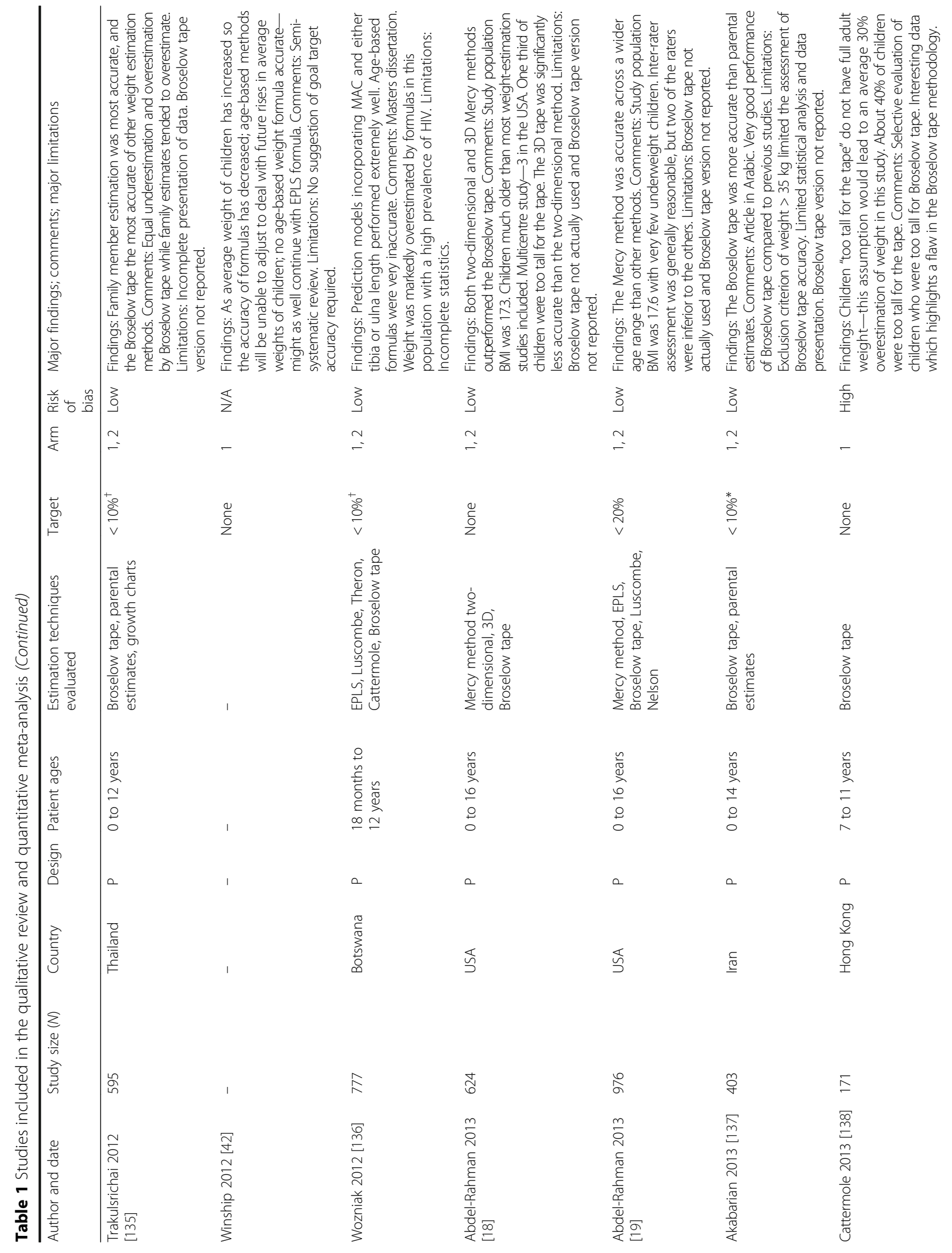




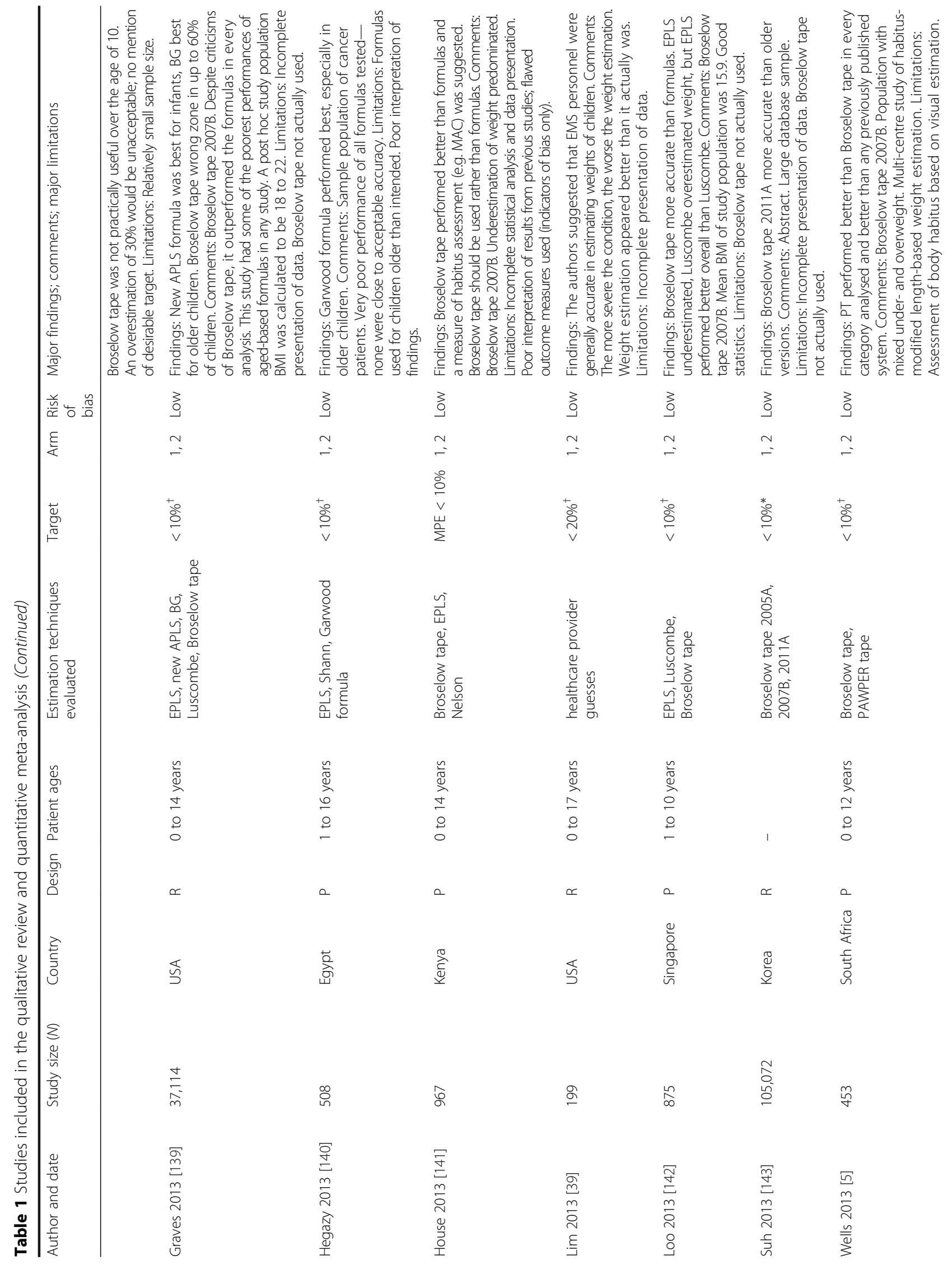




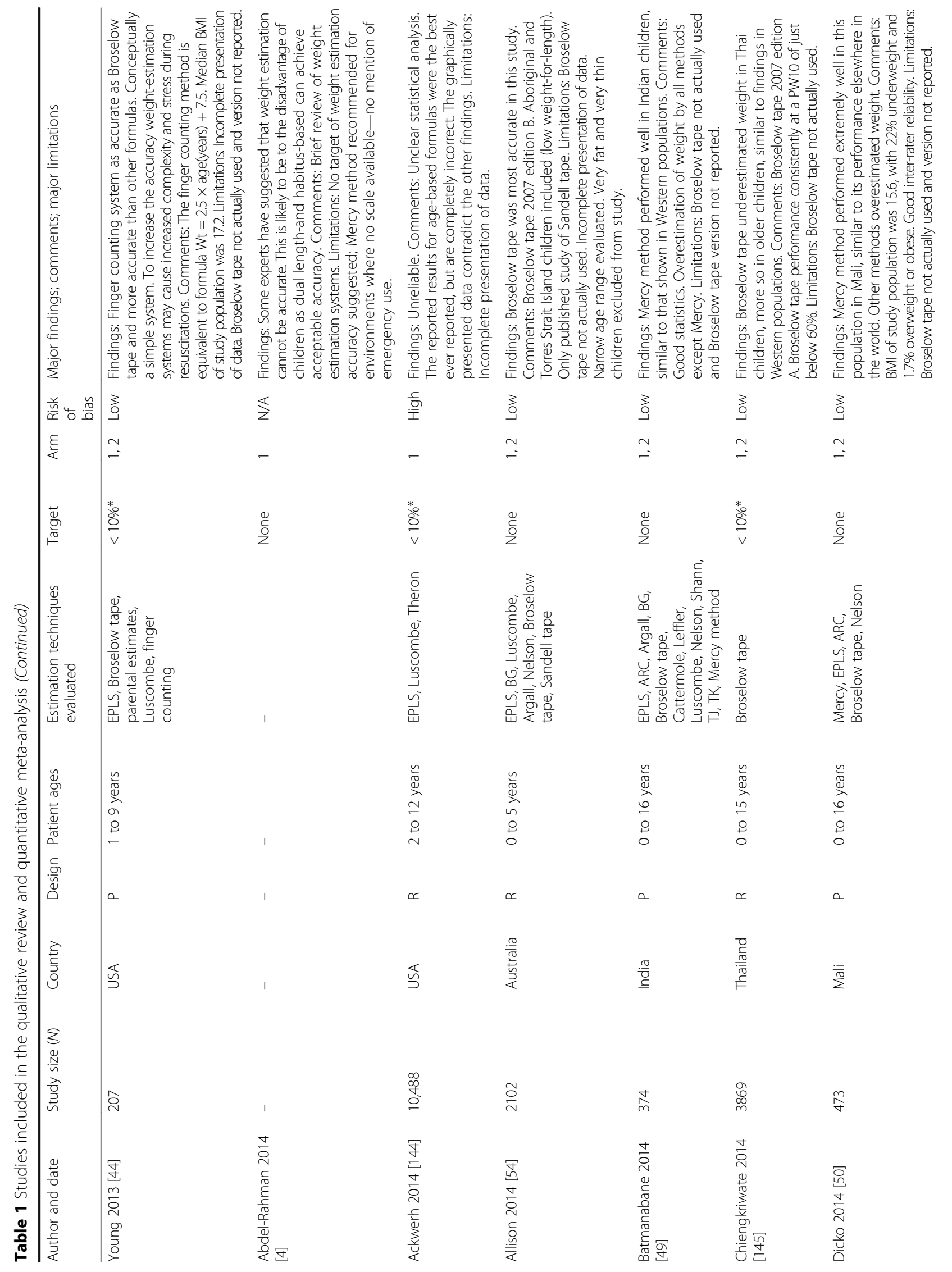




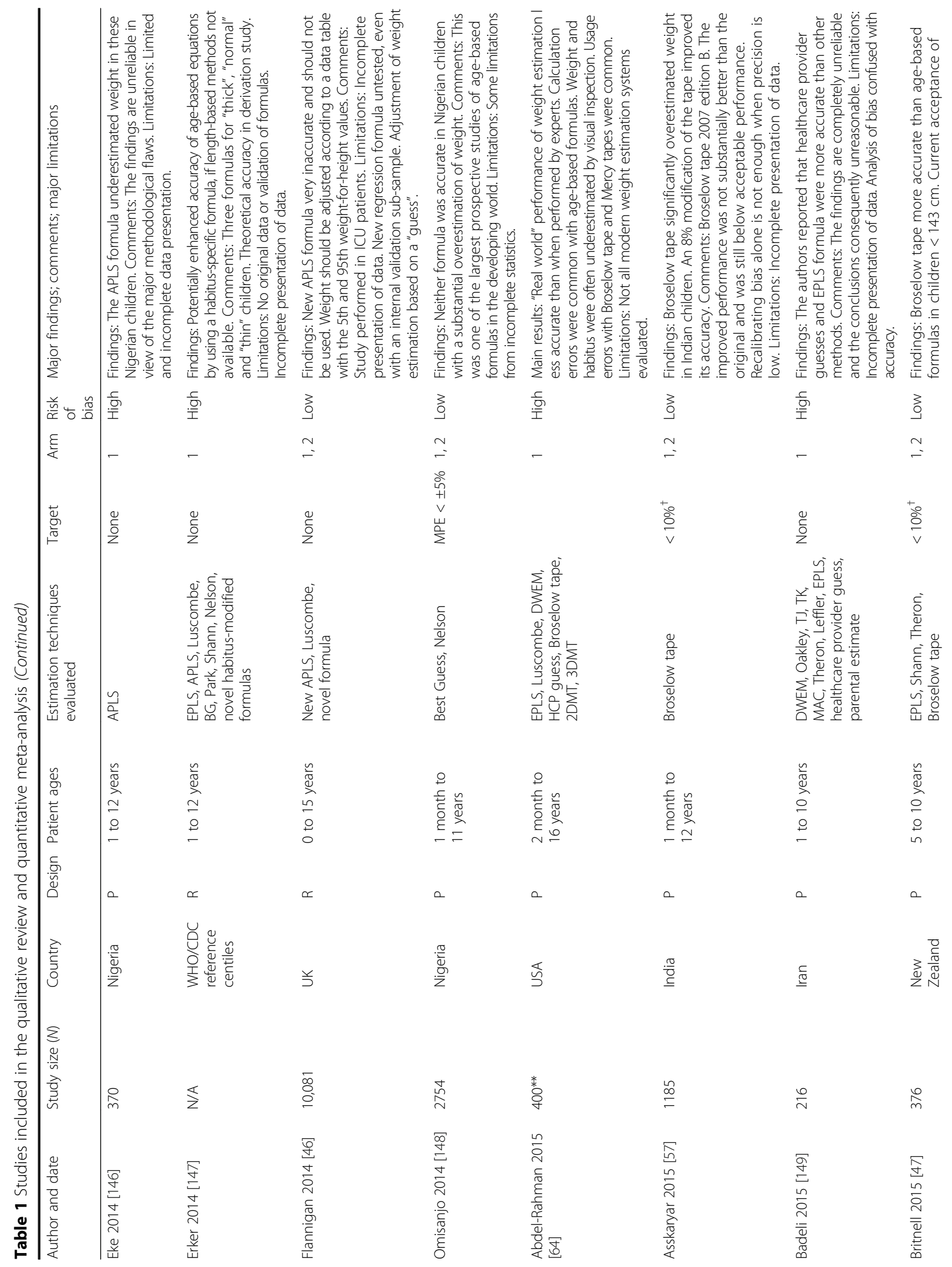




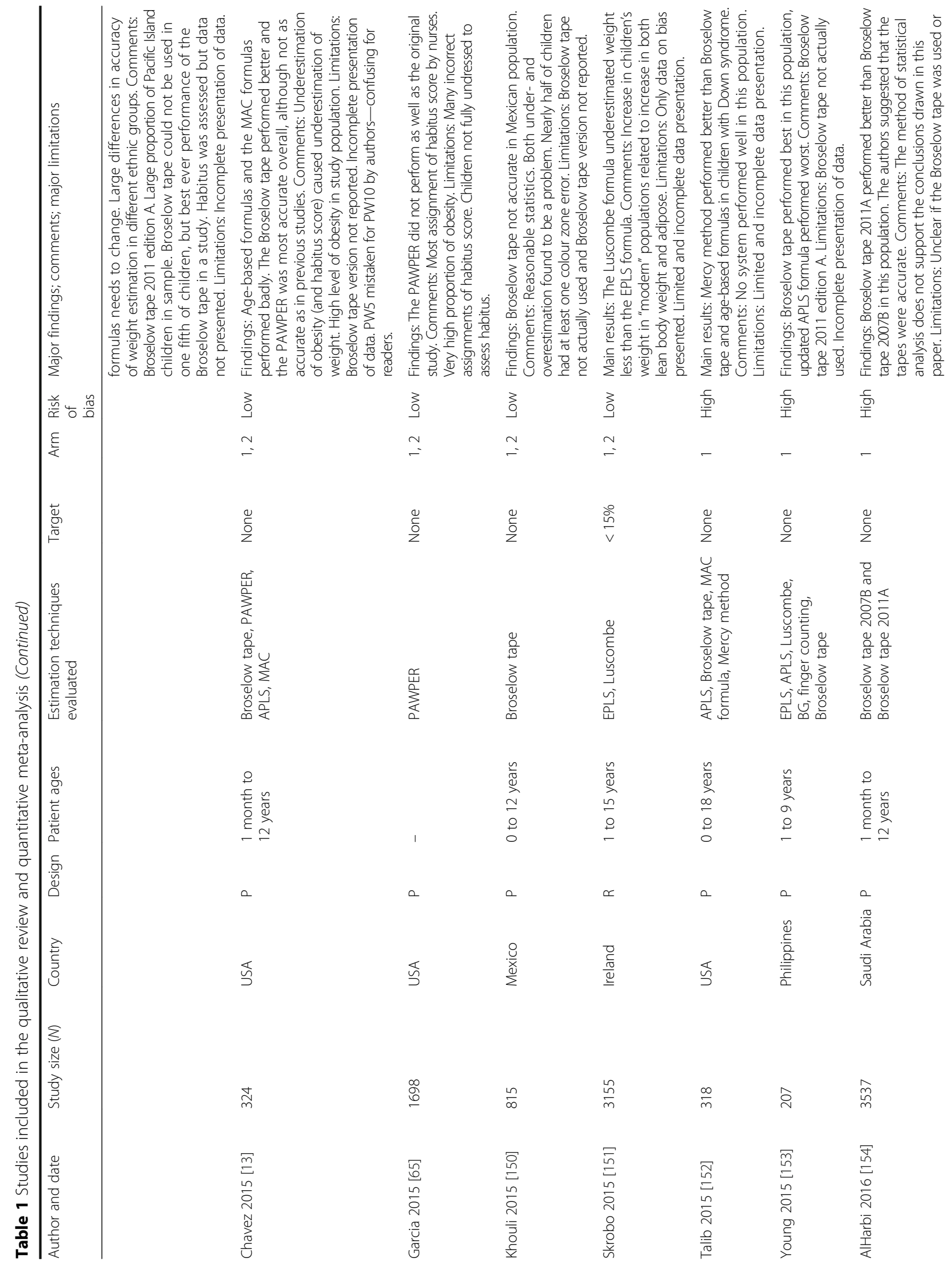




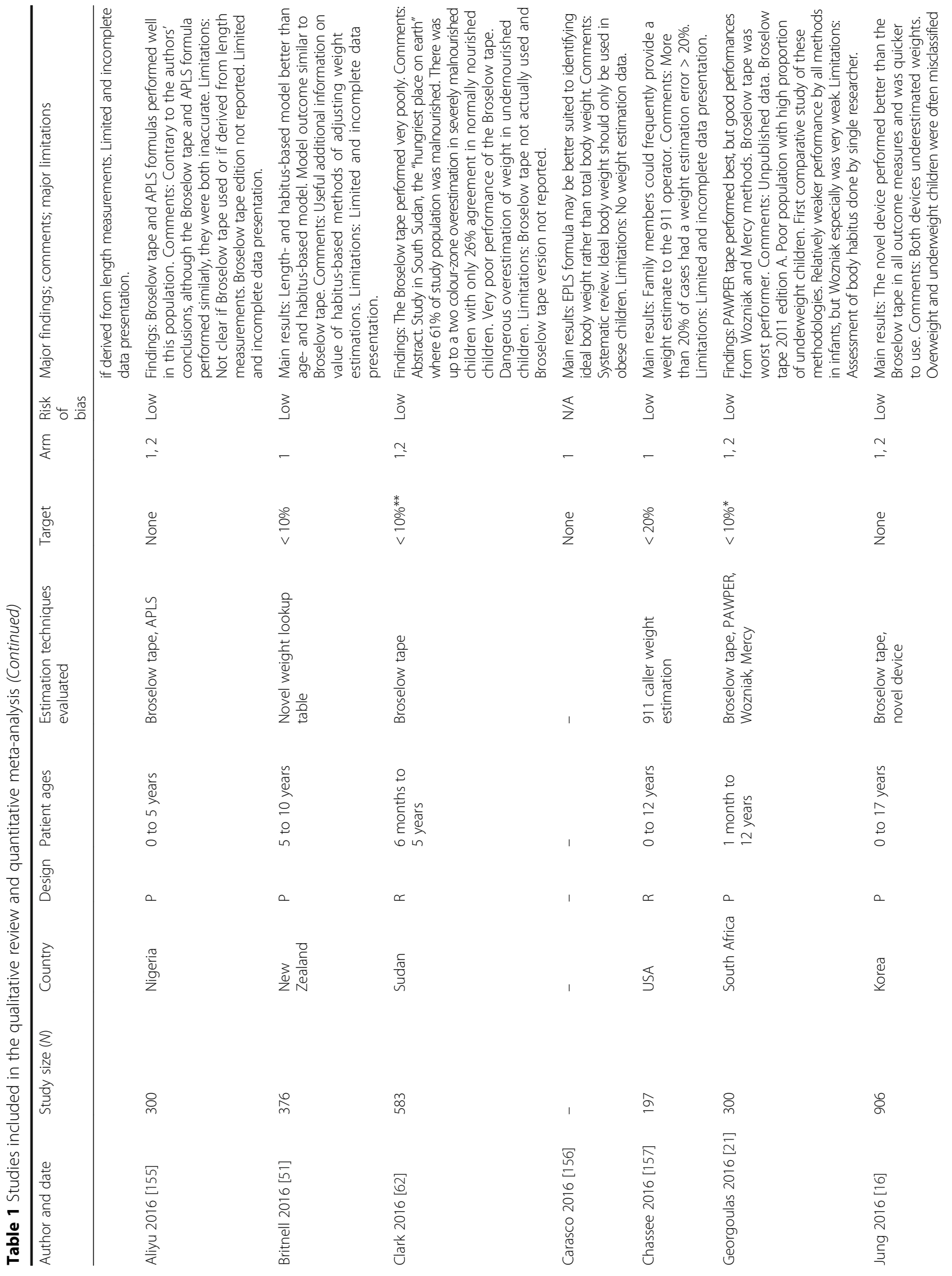




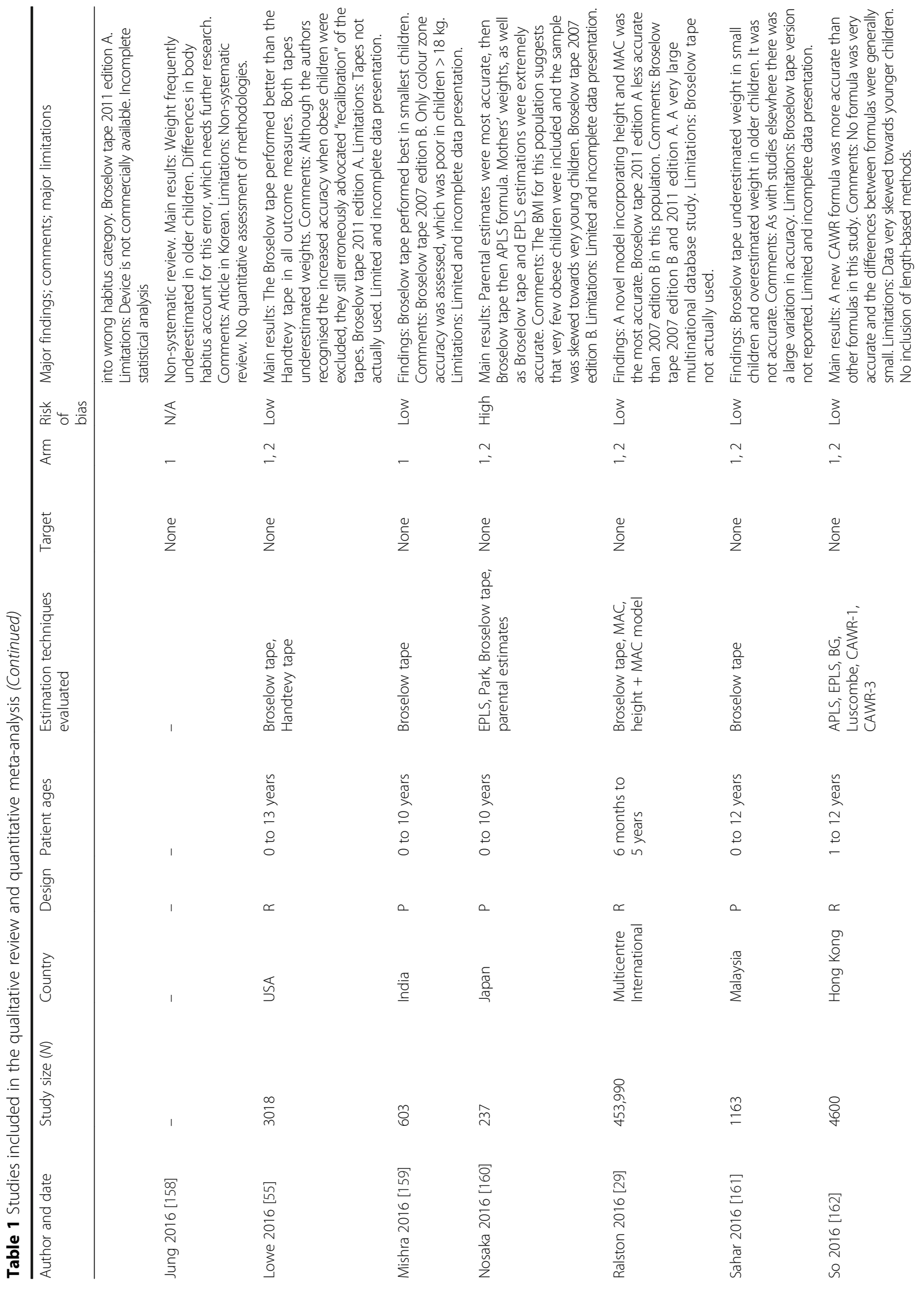




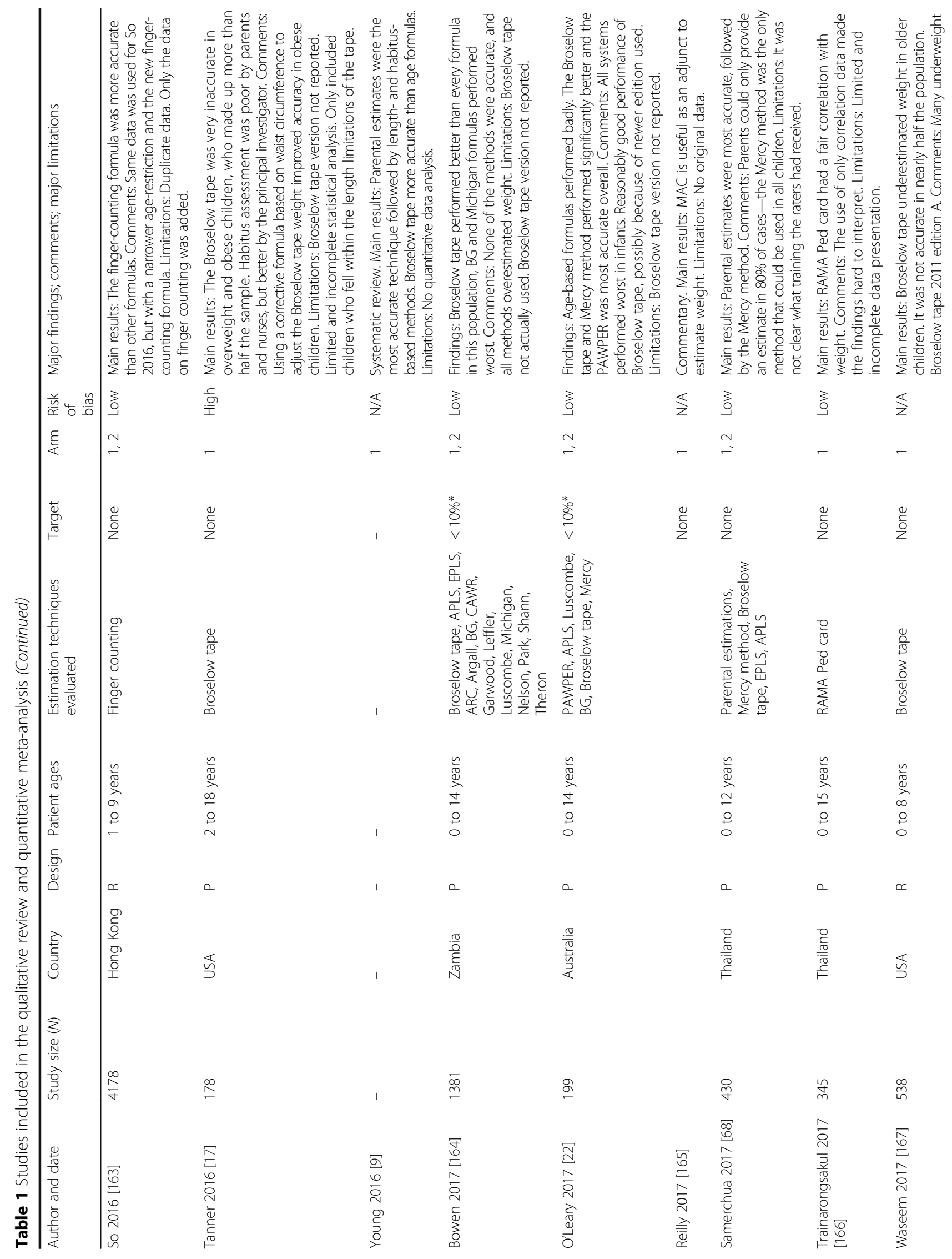




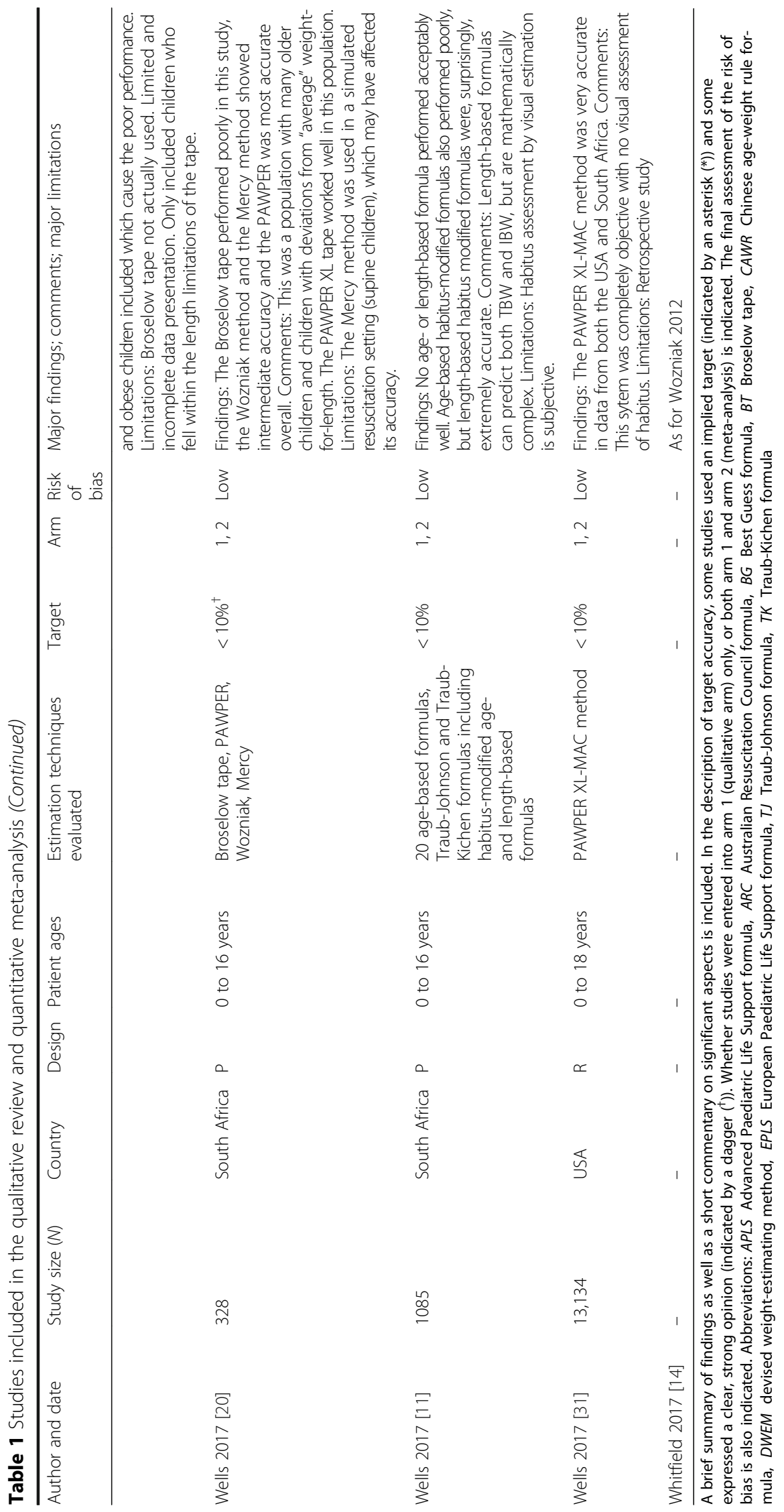




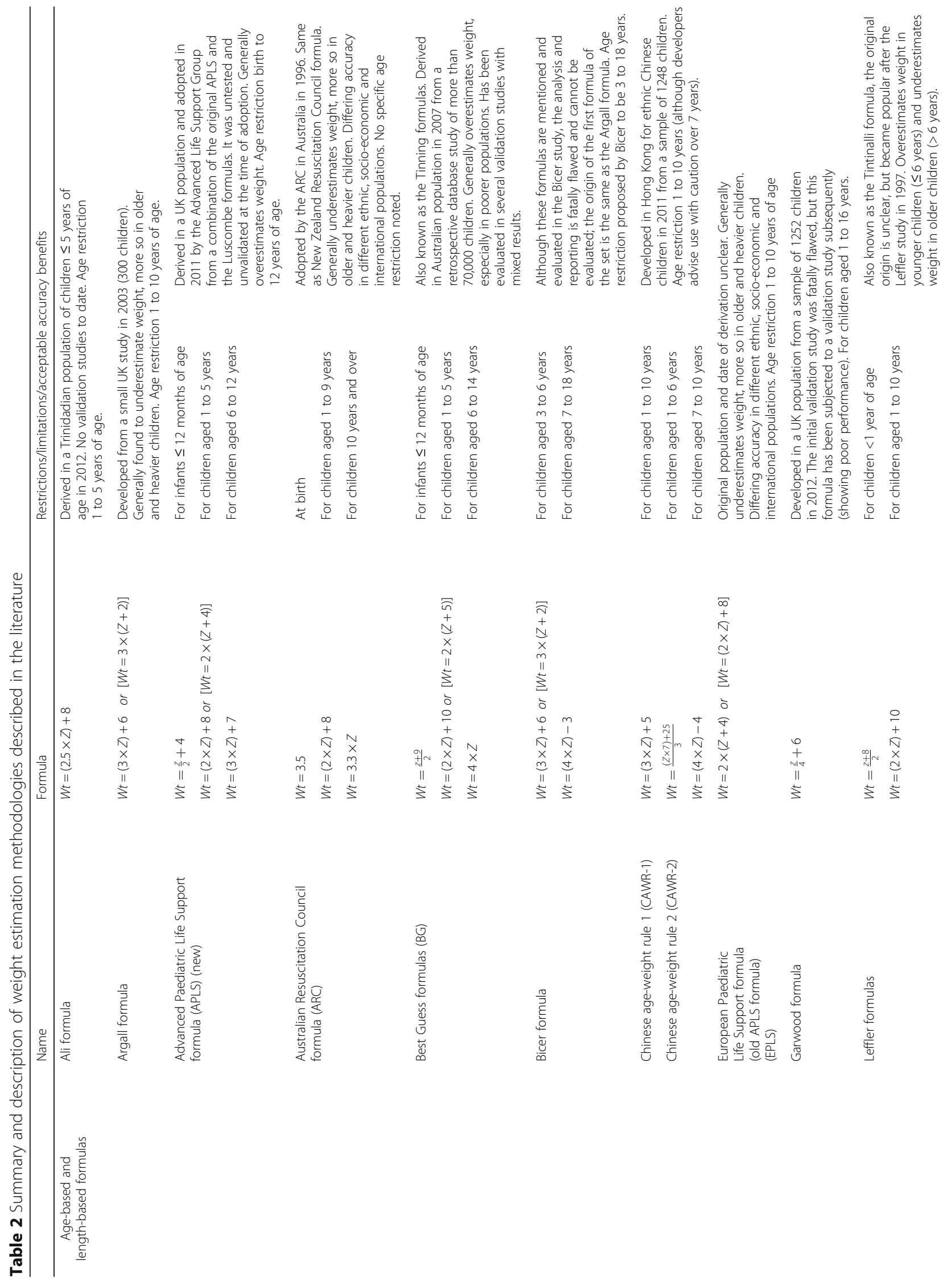




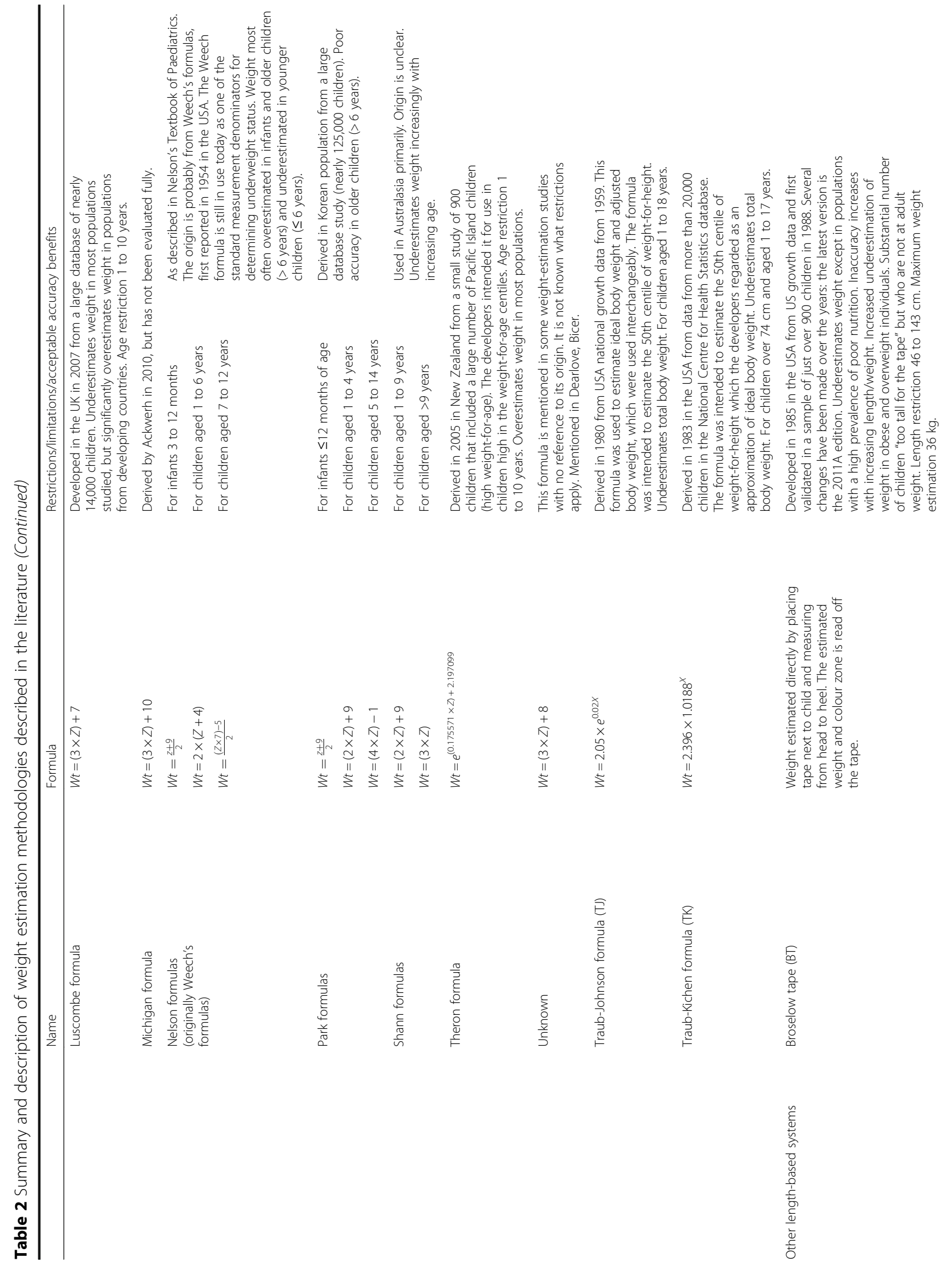




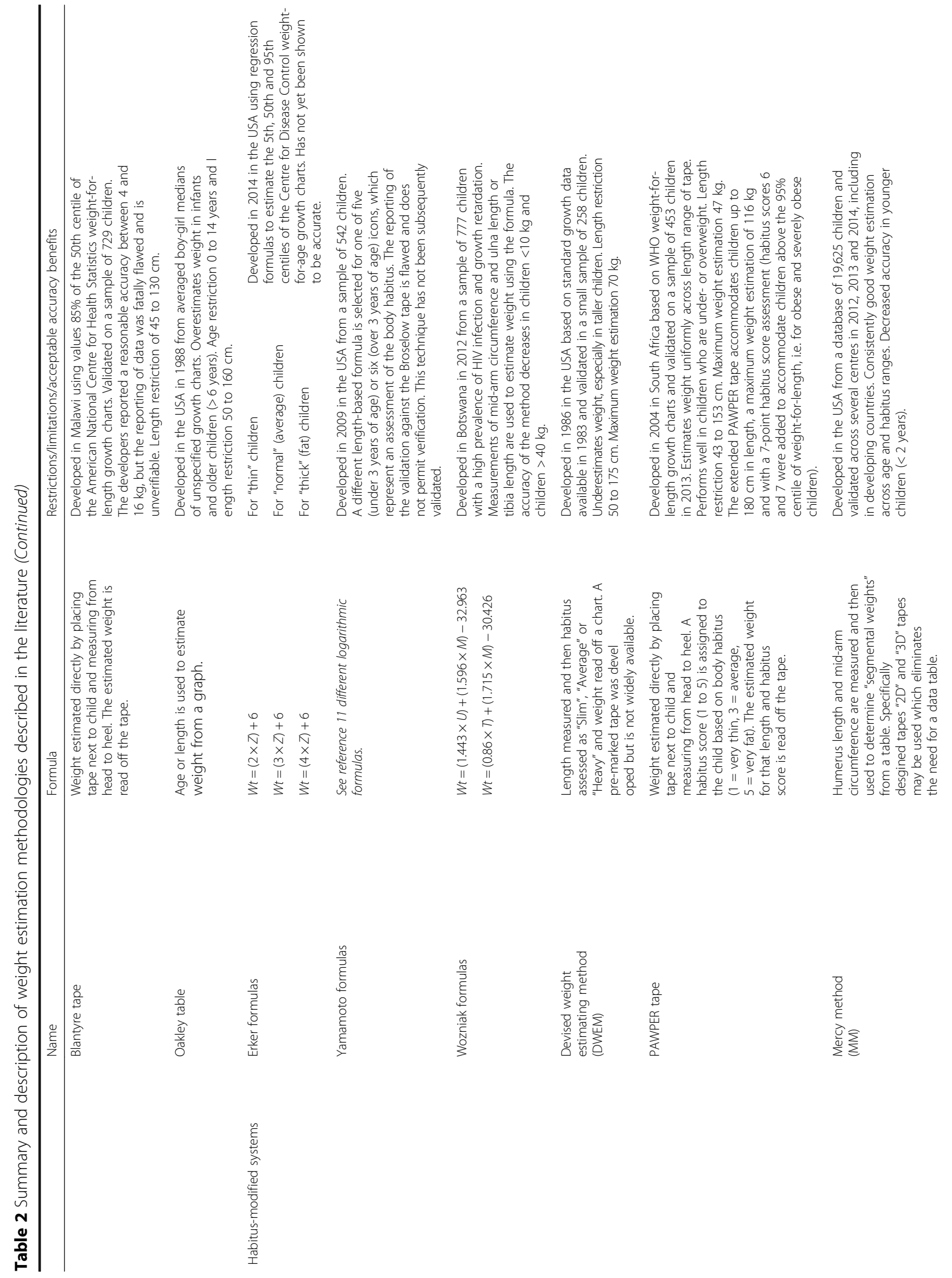




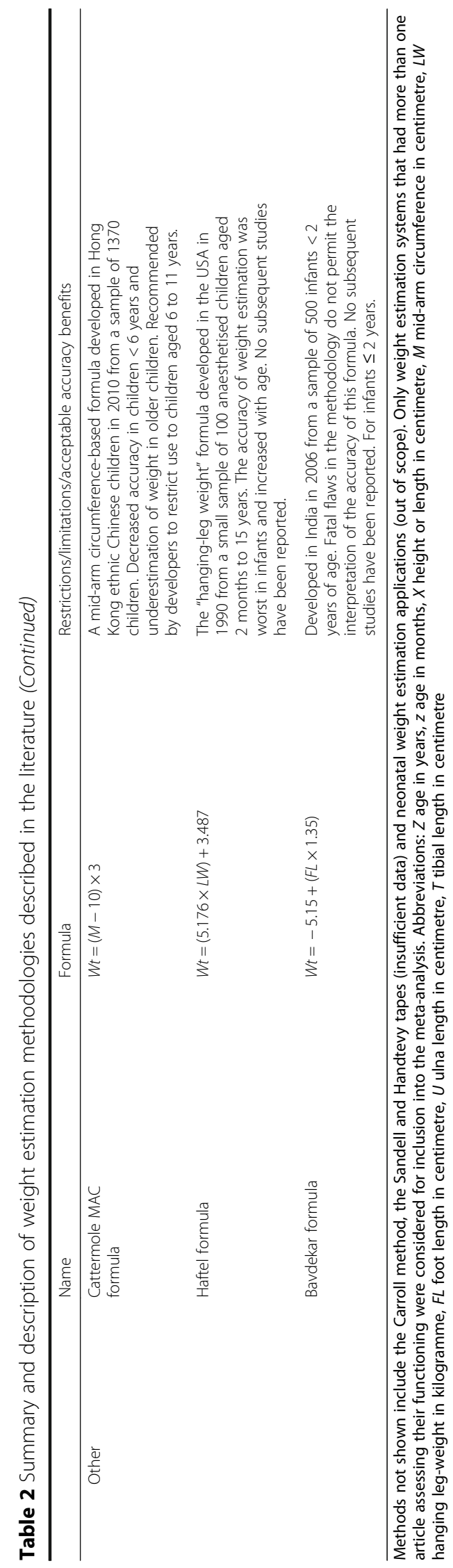




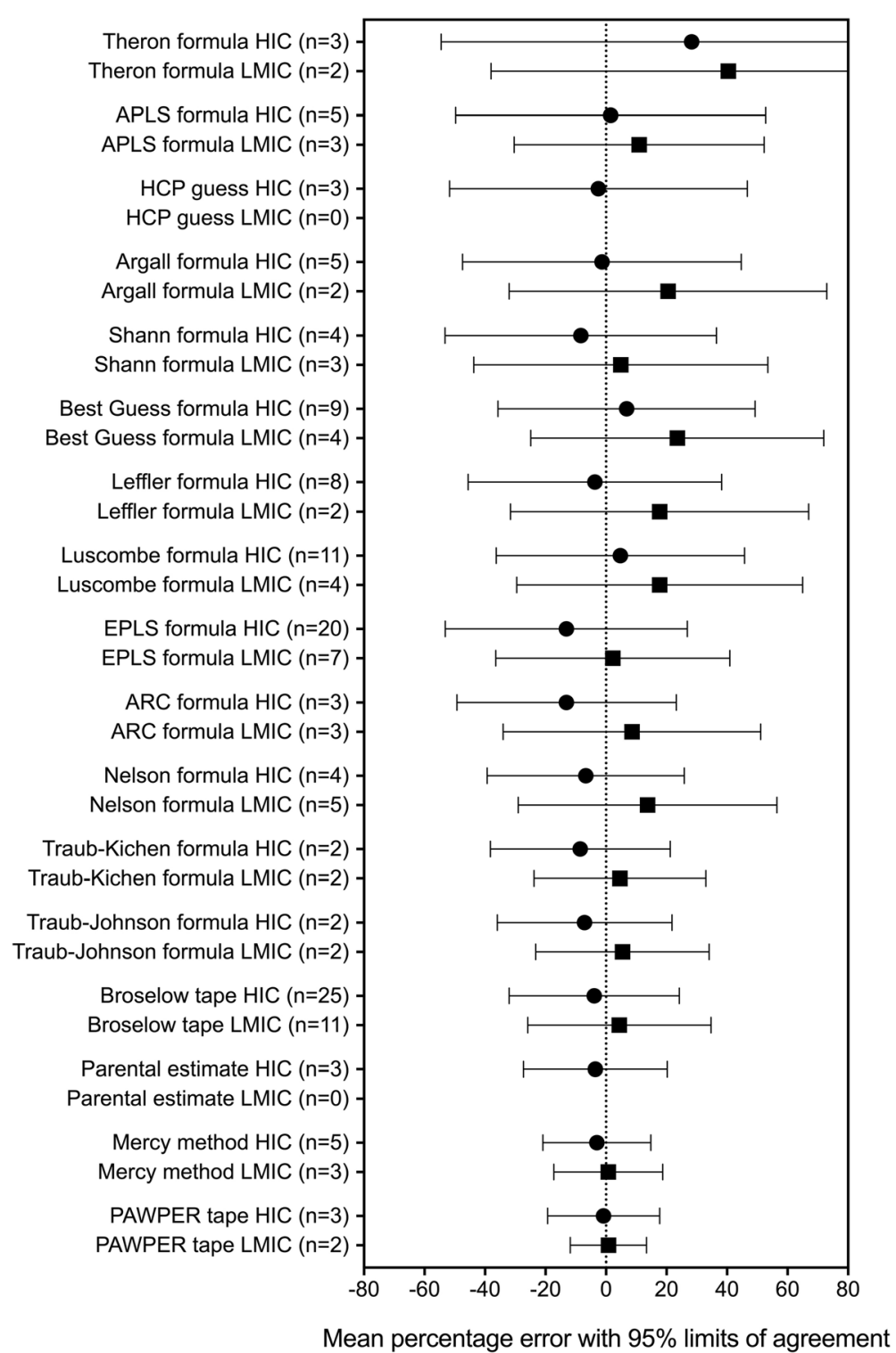

Fig. 2 Forest plot showing the bias and precision data of the major weight estimation systems evaluated

two-dimensional systems were the most accurate. Despite the difference in bias between high-income countries and low- and middle-income countries for the one-dimensional systems, the overall accuracy was similarly poor. If a PW10 of 70\% were used as a benchmark of acceptable accuracy, only the PAWPER tape and the Mercy method would have achieved acceptable accuracy, with parental estimates close behind. When examining the PW20 data in Table 3, only the PAWPER tape (96.6\%) and the Mercy method (95.3\%) met the acceptability criteria suggested by Stewart of a PW20 > 95\% [30]. The PW20s for the Broselow tape, parental estimates and a value calculated for pooled age-based formulas were $81.2,87.1$ and $65.0 \%$, respectively.
The results of the subgroup analyses are shown in Table 4.

Figure 4 shows the results of direct statistical comparisons between weight estimation systems from studies where paired data could be pooled, using nonparametric measures of accuracy (PW10 data). The full analyses are available in Additional file 2: Figure S1. There was little difference between the accuracy of the different age formulas. Length-based methods were always more accurate than age-based methods, and twodimensional methods were more accurate than onedimensional methods. On direct comparison, but with data from only two studies, the PAWPER tape was significantly more accurate than the Mercy method. 
Parental estimates were significantly more accurate than the Broselow tape, but there was no data for direct comparison with any two-dimensional system.

\section{Discussion}

\section{Summary}

The quality of the evidence from the contributing studies was generally good, and the number of studies that could be included allowed for a comprehensive analysis of the data. The underlying risks of bias, while present, were considered not sufficient to alter the overall findings. Additional information on parental estimations of weight in different populations and circumstances is also required, as well as a comparison with the twodimensional weight estimation systems.

The implications of the results for clinical practice and future research are profound: age-based formulas, along with healthcare provider guesses, were the least accurate of all weight estimation systems. They should not be used or taught. Similarly, one-dimensional length-based systems, while widely used and advocated by advanced life support organisations, were simply not accurate enough. The future challenges will be to develop twodimensional systems, which produced the most accurate weight estimations, to be safe, quick and easy-to-use during emergency care.

Many articles on weight estimation have been-and continue to be-published without any clear indication if the results achieved, and the weight estimation systems tested, were actually good or bad. This metaanalysis has provided some useful findings which could guide researchers and decision-makers on which systems to use in clinical practice and which to explore in further research. It has also provided some perspective on the performance of weight estimation systems in highincome and low-and middle-income populations, which is important as most weight estimation systems have been developed in high-income countries and have the potential to be dangerous if used inappropriately.

\section{A benchmark for weight estimation systems}

What degree of under- or overestimation of weight is dangerous to a child when calculating drug doses is not known [34, 35]. Many of the drugs used in paediatric emergencies have not been adequately studied to determine optimal dosing ranges. Moreover, the consequences of overestimating or underestimating weight (and therefore dose) will differ between different drugs, different patients and different clinical scenarios [36-39]. The final dose will be strongly influenced by the clinical situation and the discretion of the treating doctor, but an accurate and reliable weight estimation would still be required to provide the starting point to allow for dose modifications.
Some authors regard the need for a highly accurate weight estimation as debatable. Other argue that any factors potentially impacting on patient safety must be addressed and minimised, especially in the light of compounded errors in drug dose calculations [40].

In the qualitative arm of the systematic review, we found no objective evidence to support any particular target or system by which to assess the adequacy of weight estimation methodologies. The failure to define outcome measures on how accurately a weight estimation method must perform is methodologically unsound, however. This is important as the use of a system known to be inaccurate, or inferior to another system is not good medical practice [1]. There are clearly factors other than accuracy to consider when selecting the most appropriate weight system to adopt including the complexity and cognitive load generated by the system, the vulnerability to human factor errors and its ability to interface with a drug dosing guide [41]. This needs further research.

Despite the lack of objective evidence, some reference standard is still required. A large number of articles implied or stated explicitly that an individual estimation of weight within $10 \%$ of actual weight is desirable, but only three articles provided a benchmark by which to judge a weight estimation system. The suggested criteria were that, to be considered accurate, $70 \%$ of weight estimates must be within $10 \%$ of actual weight and $95 \%$ of weight estimates must fall within $20 \%$ of actual weight [11, 30, 31]. Since the newest two-dimensional systems have shown the capability to repeatedly achieve this standard, it could, therefore, be considered a reasonable benchmark to propose to assess the adequacy of weight estimation systems in the future.

\section{Meta-analysis data: the accuracy of weight estimation systems}

Age-based weight estimation

The age-based formulas were the least accurate and worst-performers of all the weight estimation methods. There are multiple reasons for the inaccuracy of age-based formulas: a large biological variability in weight-for-age; a non-linear relationship between weight and age; and differences between populations with different ethnic groups and different levels of nutrition [10]. We found that age-based formulas have never been shown to perform better than length-based systems. Despite this, many authors still regard the EPLS formula as the "gold standard" for weight estimation and age-formulas are still taught on advanced life support courses $[42,43]$. Some authors also still support the use of age-based formulas because of their ostensible simplicity, because they require no equipment to function and they allow advanced preparation if emergency services 


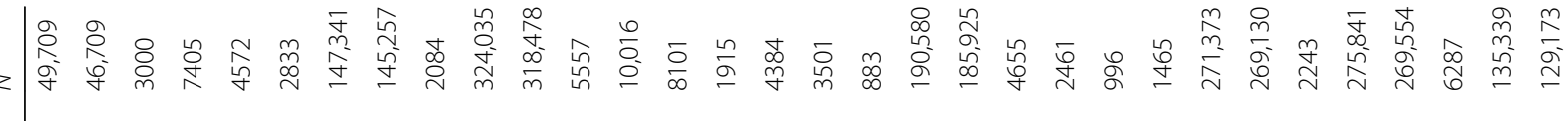
$\frac{\tilde{w}}{\bar{m}}$

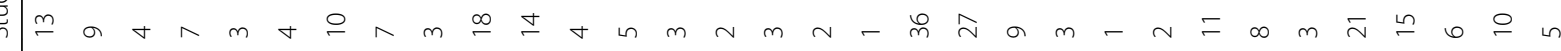

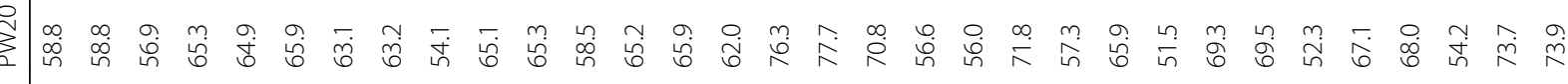

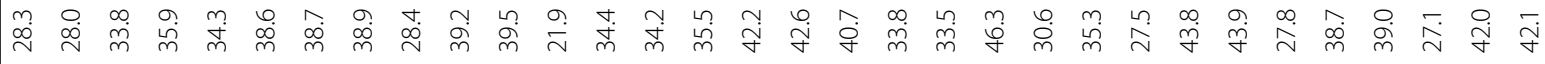

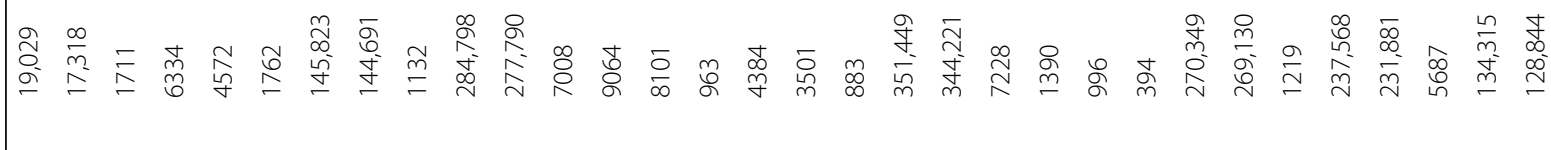

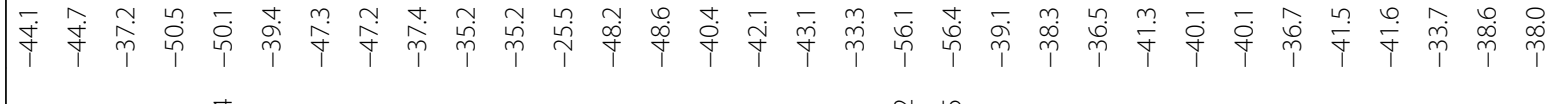

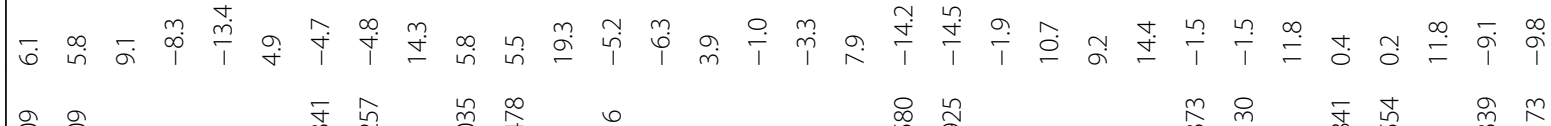

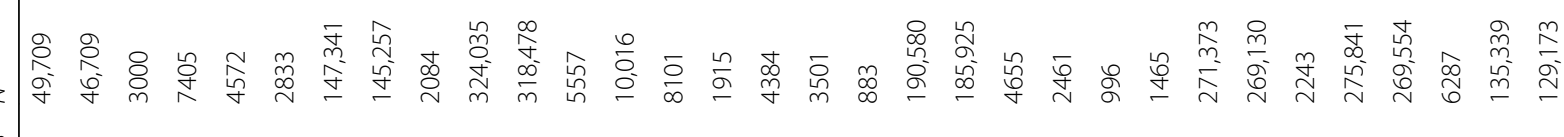

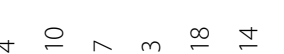
n $m \sim m \sim$

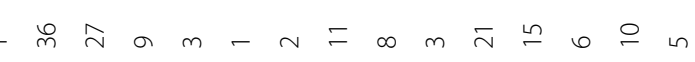

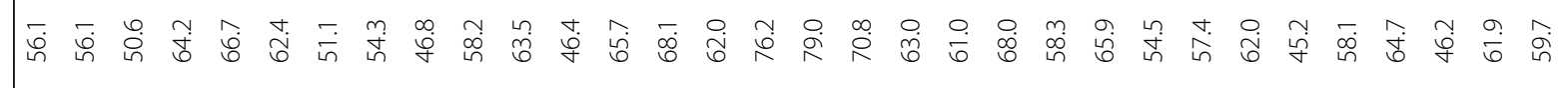

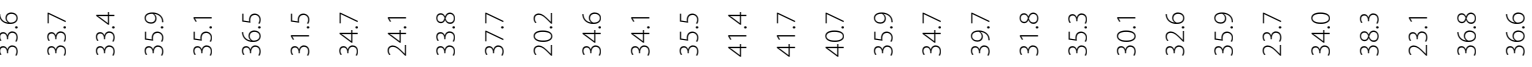

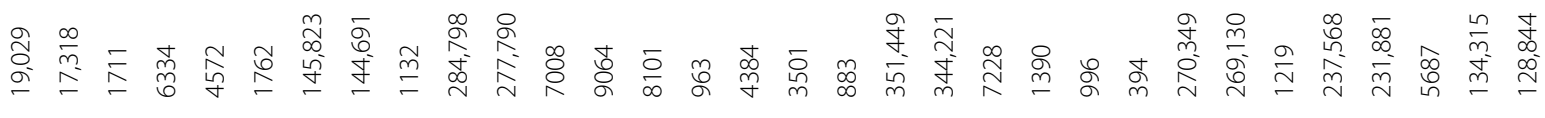

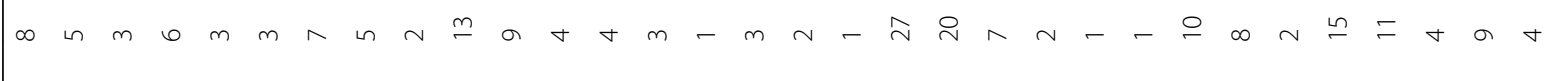

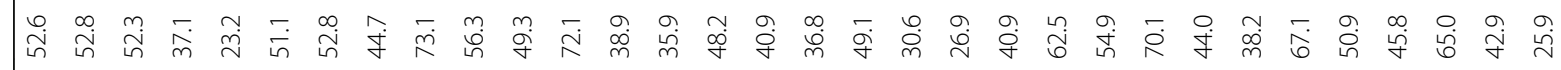

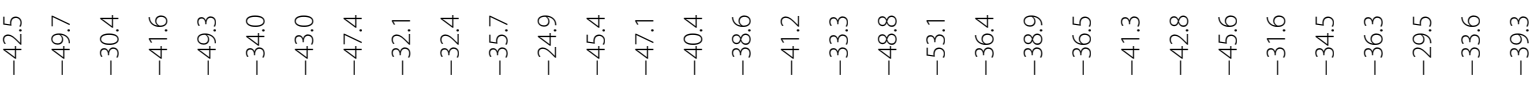

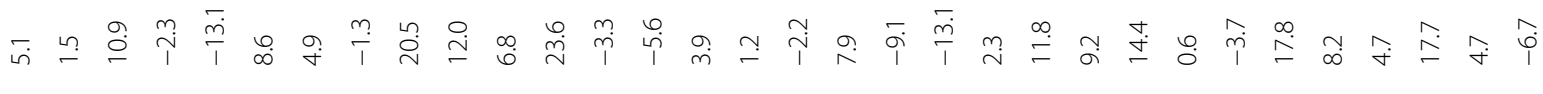

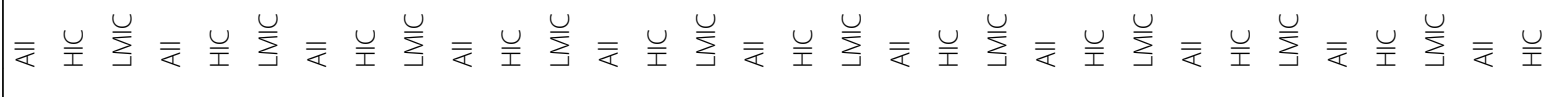




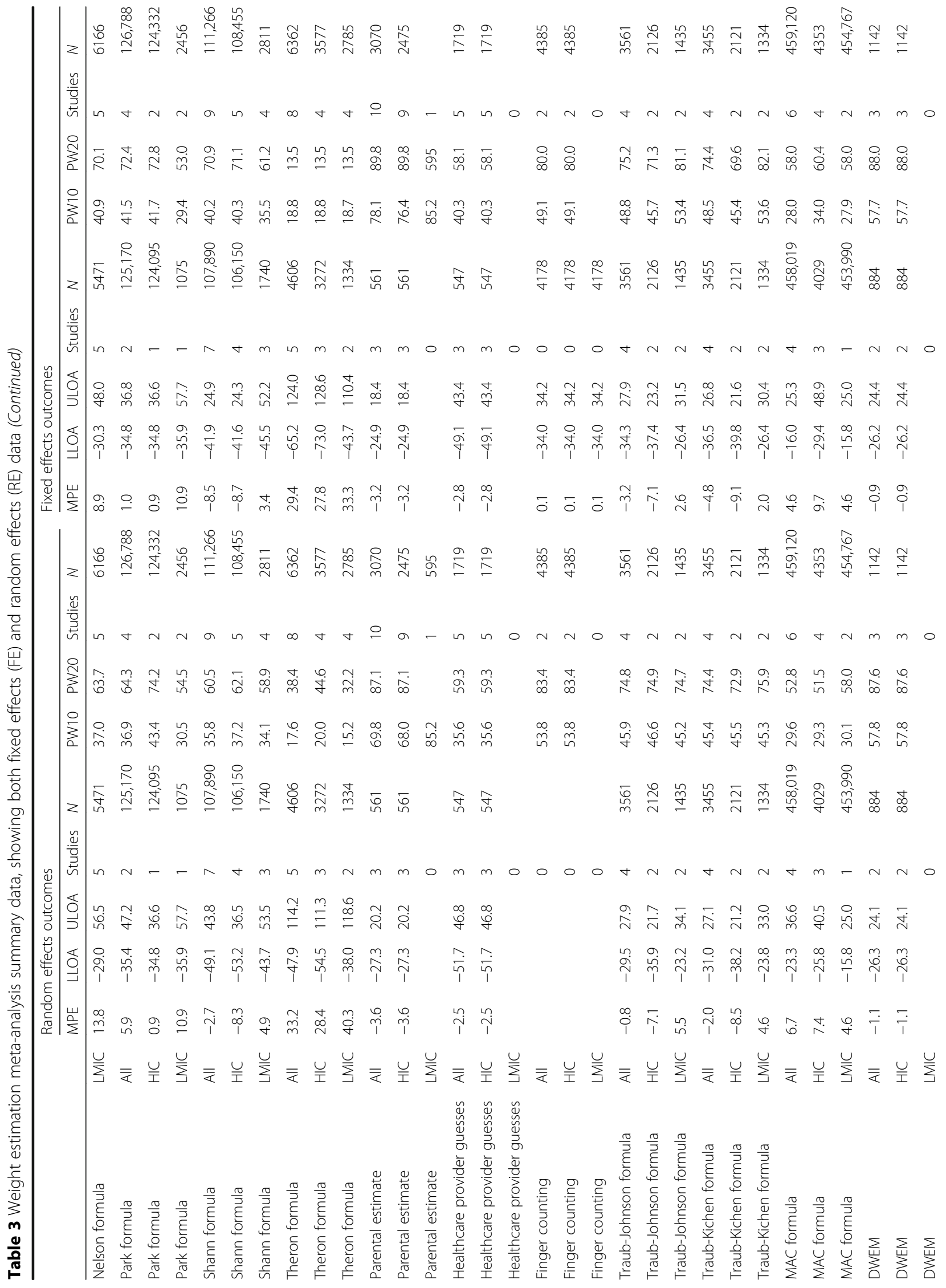




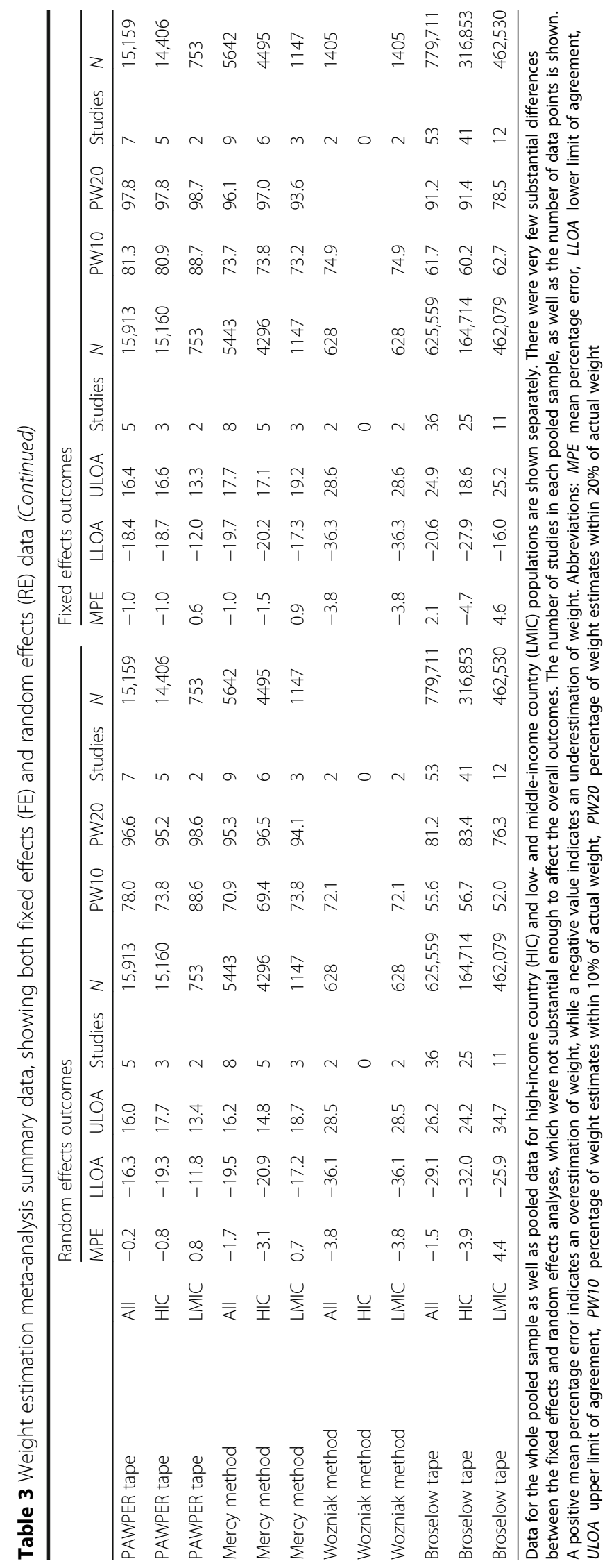




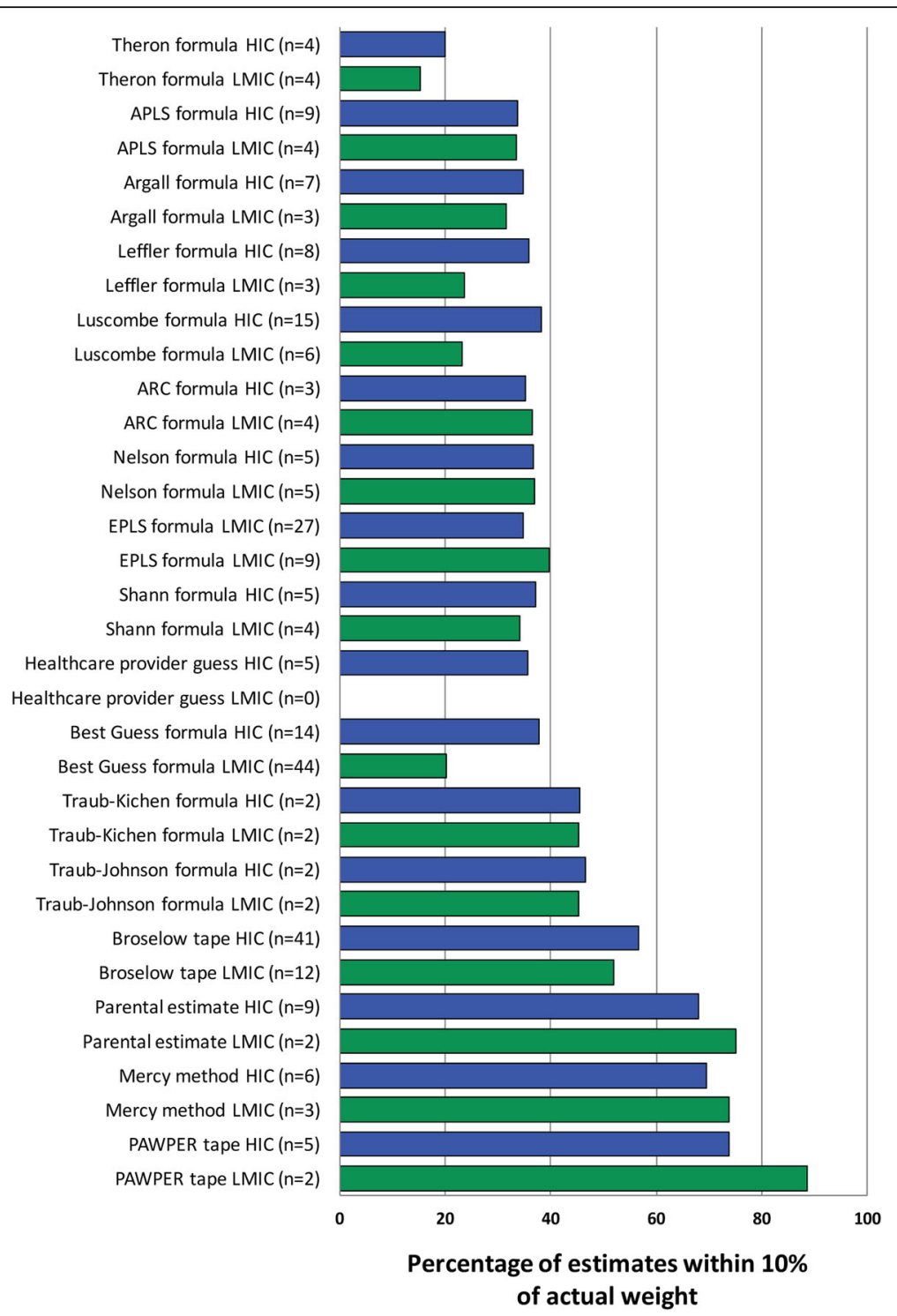

Fig. 3 A bar chart showing the accuracy data of the major weight estimation systems evaluated

personnel communicate a child's age during transport to hospital [35]. However, their use presupposes that a child's correct age is known, that the formula is remembered correctly and that the arithmetic is performed accurately. Memory is capricious in emergencies, however, and increased stress causes errors even in calculating simple formulas [44]. The benefits of the formulas are unlikely to mitigate for their very poor accuracy [11].

Many studies have shown age-based formulas to underestimate weight in first-world populations [45-47], but studies in low- and middle-income countries have shown a significant, potentially dangerous overestimation of weight by the same formulas [48-50]. In this meta-analysis, this was confirmed, with no age-based formula performing well in any population, but the overestimation of weight in low- and middle-income populations was significant and potentially unsafe. Even the use of habitus-modified age-formulas has failed to produce an improvement in accuracy to the degree of accuracy seen with length-based habitus-modified systems, as this modification still does not account for variations in length-for-age [11, 51].

This futility of age-based weight estimation can be perfectly summed up: "Accurate paediatric weight estimation by age: mission impossible" [27]. The unavoidable conclusion is that age-based formulas should no longer be used and clinicians that manage children should ensure that a better weight-estimation system is available for use during emergency care [11, 47, 52]. 
Table 4 Subgroup data for each weight estimation system

\begin{tabular}{|c|c|c|c|c|c|c|c|c|}
\hline System & Subgroup & & $\begin{array}{l}\text { Mean } \\
\text { percentage } \\
\text { error }\end{array}$ & $\begin{array}{l}\text { Lower limit } \\
\text { of } \\
\text { agreement }\end{array}$ & $\begin{array}{l}\text { Upper limit } \\
\text { of } \\
\text { agreement }\end{array}$ & $\begin{array}{l}\text { Number of children } \\
\text { (number of studies) }\end{array}$ & PW10 & $\begin{array}{l}\text { Number of children } \\
\text { (number of studies) }\end{array}$ \\
\hline \multirow[t]{3}{*}{$\begin{array}{l}\text { APLS formula } \\
\text { (new) }\end{array}$} & Age $<1$ & $\begin{array}{l}\mathrm{FE} \\
\mathrm{RE}\end{array}$ & $\begin{array}{l}19.4 \\
8.2\end{array}$ & $\begin{array}{l}-30.7 \\
-54.5\end{array}$ & $\begin{array}{l}69.4 \\
70.8\end{array}$ & $5388(2)$ & $\begin{array}{l}23.5 \\
30.2\end{array}$ & $5700(4)$ \\
\hline & Age 1-5 & $\begin{array}{l}\mathrm{FE} \\
\mathrm{RE}\end{array}$ & $\begin{array}{l}-6.0 \\
-8.2\end{array}$ & $\begin{array}{l}-45.2 \\
-53.6\end{array}$ & $\begin{array}{l}33.3 \\
37.2\end{array}$ & 4438 (3) & $\begin{array}{l}37.3 \\
35.0\end{array}$ & $8941(5)$ \\
\hline & Age 6-12 & $\begin{array}{l}\mathrm{FE} \\
\mathrm{RE}\end{array}$ & $\begin{array}{l}7.3 \\
3.8\end{array}$ & $\begin{array}{l}-50.7 \\
-56.2\end{array}$ & $\begin{array}{l}65.2 \\
63.8\end{array}$ & 2462 (3) & $\begin{array}{l}23.3 \\
29.9\end{array}$ & $26,338(5)$ \\
\hline \multirow[t]{2}{*}{ ARC formula } & Age 1-5 & $\begin{array}{l}\mathrm{FE} \\
\mathrm{RE}\end{array}$ & $\begin{array}{l}-10.1 \\
-9.8\end{array}$ & $\begin{array}{l}-39.4 \\
-39.0\end{array}$ & $\begin{array}{l}19.2 \\
19.4\end{array}$ & $1415(2)$ & $\begin{array}{l}43.4 \\
44.2\end{array}$ & 1415 (2) \\
\hline & Age 6-10 & $\begin{array}{l}\mathrm{FE} \\
\mathrm{RE}\end{array}$ & $\begin{array}{l}-12.4 \\
-12.5\end{array}$ & $\begin{array}{l}-53.4 \\
-53.5\end{array}$ & $\begin{array}{l}28.5 \\
28.6\end{array}$ & $1405(2)$ & $\begin{array}{l}33.2 \\
33.3\end{array}$ & $1405(2)$ \\
\hline \multirow[t]{2}{*}{ Argall formula } & Age 1-5 & $\begin{array}{l}\mathrm{FE} \\
\mathrm{RE}\end{array}$ & 3.8 & -30.1 & 37.7 & $609(1)$ & $\begin{array}{l}34.1 \\
30.2\end{array}$ & $884(2)$ \\
\hline & Age 6-10 & $\begin{array}{l}\mathrm{FE} \\
\mathrm{RE}\end{array}$ & 6.8 & -36.9 & 50.5 & $639(1)$ & $\begin{array}{l}27.8 \\
25.0\end{array}$ & $741(2)$ \\
\hline \multirow[t]{3}{*}{$\begin{array}{l}\text { Best Guess } \\
\text { formula }\end{array}$} & Age $<1$ & $\begin{array}{l}\mathrm{FE} \\
\mathrm{RE}\end{array}$ & $\begin{array}{l}2.4 \\
4.1\end{array}$ & $\begin{array}{l}-42.8 \\
-43.9\end{array}$ & $\begin{array}{l}47.6 \\
52.1\end{array}$ & $20,846(5)$ & $\begin{array}{l}33.7 \\
38.4\end{array}$ & $21,083(7)$ \\
\hline & Age 1-5 & $\begin{array}{l}\mathrm{FE} \\
\mathrm{RE}\end{array}$ & $\begin{array}{l}5.0 \\
5.1\end{array}$ & $\begin{array}{l}-24.0 \\
-20.0\end{array}$ & $\begin{array}{l}34.1 \\
30.2\end{array}$ & $46,271(7)$ & $\begin{array}{l}48.8 \\
44.1\end{array}$ & $50,774(9)$ \\
\hline & Age 6-14 & $\begin{array}{l}\mathrm{FE} \\
\mathrm{RE}\end{array}$ & $\begin{array}{l}6.7 \\
9.9\end{array}$ & $\begin{array}{l}-32.5 \\
-37.8\end{array}$ & $\begin{array}{l}45.9 \\
57.5\end{array}$ & $67,028(6)$ & $\begin{array}{l}32.2 \\
31.4\end{array}$ & $99,475(9)$ \\
\hline \multirow[t]{2}{*}{$\begin{array}{l}\text { Chinese age- } \\
\text { weight rule } 1\end{array}$} & Age 1-5 & $\begin{array}{l}\mathrm{FE} \\
\mathrm{RE}\end{array}$ & $\begin{array}{l}-12.2 \\
-9.6\end{array}$ & $\begin{array}{l}-51.3 \\
-45.8\end{array}$ & $\begin{array}{l}26.8 \\
26.6\end{array}$ & $1865(2)$ & $\begin{array}{l}33.0 \\
35.5\end{array}$ & $1865(2)$ \\
\hline & Age 6-10 & $\begin{array}{l}\mathrm{FE} \\
\mathrm{RE}\end{array}$ & $\begin{array}{l}-2.6 \\
-1.5\end{array}$ & $\begin{array}{l}-50.1 \\
-47.5\end{array}$ & $\begin{array}{l}44.9 \\
44.5\end{array}$ & $1636(2)$ & $\begin{array}{l}32.5 \\
32.1\end{array}$ & $1636(2)$ \\
\hline \multirow[t]{2}{*}{$\begin{array}{l}\text { Chinese age- } \\
\text { weight rule } 2\end{array}$} & Age 1-5 & $\begin{array}{l}\mathrm{FE} \\
\mathrm{RE}\end{array}$ & $\begin{array}{l}-1.9 \\
-0.9\end{array}$ & $\begin{array}{l}-33.9 \\
-32.7\end{array}$ & $\begin{array}{l}30.0 \\
30.9\end{array}$ & $1865(2)$ & $\begin{array}{l}49.1 \\
48.0\end{array}$ & $1865(2)$ \\
\hline & Age 6-10 & $\begin{array}{l}\mathrm{FE} \\
\mathrm{RE}\end{array}$ & $\begin{array}{l}-4.9 \\
-3.8\end{array}$ & $\begin{array}{l}-52.1 \\
-49.5\end{array}$ & $\begin{array}{l}42.3 \\
41.9\end{array}$ & $1636(2)$ & $\begin{array}{l}33.9 \\
33.3\end{array}$ & $1636(2)$ \\
\hline \multirow[t]{2}{*}{ EPLS formula } & Age 1-5 & $\begin{array}{l}\mathrm{FE} \\
\mathrm{RE}\end{array}$ & $\begin{array}{l}-12.7 \\
-9.9\end{array}$ & $\begin{array}{l}-43.4 \\
-42.6\end{array}$ & $\begin{array}{l}18.0 \\
22.9\end{array}$ & $91,652(11)$ & $\begin{array}{l}37.9 \\
41.5\end{array}$ & 96,077 (12) \\
\hline & Age 6-10 & $\begin{array}{l}\mathrm{FE} \\
\mathrm{RE}\end{array}$ & $\begin{array}{l}-18.3 \\
-19.4\end{array}$ & $\begin{array}{l}-61.7 \\
-63.8\end{array}$ & $\begin{array}{l}25.0 \\
24.9\end{array}$ & $101,742(11)$ & $\begin{array}{l}29.0 \\
28.1\end{array}$ & $116,988(12)$ \\
\hline \multirow[t]{3}{*}{ Leffler formula } & Age $<1$ & $\begin{array}{l}\mathrm{FE} \\
\mathrm{RE}\end{array}$ & $\begin{array}{l}-5.7 \\
8.8\end{array}$ & $\begin{array}{l}-46.1 \\
-42.8\end{array}$ & $\begin{array}{l}34.7 \\
60.4\end{array}$ & $20,325(2)$ & $\begin{array}{l}36.6 \\
27.7\end{array}$ & $20,325(2)$ \\
\hline & Age 1-5 & $\begin{array}{l}\mathrm{FE} \\
\mathrm{RE}\end{array}$ & $\begin{array}{l}4.2 \\
5.8\end{array}$ & $\begin{array}{l}-23.4 \\
-25.4\end{array}$ & $\begin{array}{l}31.8 \\
37.0\end{array}$ & $41,603(3)$ & $\begin{array}{l}50.3 \\
43.8\end{array}$ & $41,603(3)$ \\
\hline & Age 6-10 & $\begin{array}{l}\mathrm{FE} \\
\mathrm{RE}\end{array}$ & $\begin{array}{l}-5.0 \\
-11.0\end{array}$ & $\begin{array}{l}-39.1 \\
-45.6\end{array}$ & $\begin{array}{l}29.1 \\
23.6\end{array}$ & $64,426(3)$ & $\begin{array}{l}42.0 \\
31.9\end{array}$ & $64,426(3)$ \\
\hline \multirow[t]{2}{*}{$\begin{array}{l}\text { Luscombe } \\
\text { formula }\end{array}$} & Age 1-5 & $\begin{array}{l}\mathrm{FE} \\
\mathrm{RE}\end{array}$ & $\begin{array}{l}-3.3 \\
2.4\end{array}$ & $\begin{array}{l}-36.7 \\
-32.5\end{array}$ & $\begin{array}{l}30.1 \\
37.3\end{array}$ & $47,602(4)$ & $\begin{array}{l}43.0 \\
37.7\end{array}$ & $52,482(7)$ \\
\hline & Age 6-10 & $\begin{array}{l}\mathrm{FE} \\
\mathrm{RE}\end{array}$ & $\begin{array}{l}1.2 \\
8.5\end{array}$ & $\begin{array}{l}-45.3 \\
-35.7\end{array}$ & $\begin{array}{l}47.8 \\
52.6\end{array}$ & $34,663(4)$ & $\begin{array}{l}28.3 \\
28.9\end{array}$ & $67,435(7)$ \\
\hline \multirow[t]{3}{*}{ Nelson formula } & Age $<1$ & $\begin{array}{l}\mathrm{FE} \\
\mathrm{RE}\end{array}$ & $\begin{array}{l}-8.1 \\
-3.5\end{array}$ & $\begin{array}{l}-33.2 \\
-29.2\end{array}$ & $\begin{array}{l}16.9 \\
22.2\end{array}$ & $20,217(2)$ & $\begin{array}{l}47.9 \\
51.1\end{array}$ & $20,217(2)$ \\
\hline & Age 1-5 & $\begin{array}{l}\mathrm{FE} \\
\mathrm{RE}\end{array}$ & $\begin{array}{l}-9.1 \\
-5.7\end{array}$ & $\begin{array}{l}-32.9 \\
-32.1\end{array}$ & $\begin{array}{l}14.7 \\
20.7\end{array}$ & $42,960(3)$ & $\begin{array}{l}47.2 \\
51.8\end{array}$ & $42,960(3)$ \\
\hline & Age 6-10 & $\begin{array}{l}\mathrm{FE} \\
\mathrm{RE}\end{array}$ & $\begin{array}{l}-10.6 \\
-9.4\end{array}$ & $\begin{array}{l}-41.9 \\
-46.5\end{array}$ & $\begin{array}{l}20.7 \\
27.7\end{array}$ & $64,268(2)$ & $\begin{array}{l}38.7 \\
37.2\end{array}$ & $64,268(2)$ \\
\hline \multirow[t]{3}{*}{ Park formula } & Age $<1$ & & 2.3 & -42.8 & 47.4 & $19,854(1)$ & 33.5 & $19,854(1)$ \\
\hline & Age 1-5 & & -2.7 & -28.0 & 22.6 & $40,612(1)$ & 55.2 & $40,612(1)$ \\
\hline & Age 6-10 & & 2.7 & -34.7 & 40.1 & $63,629(1)$ & 39.6 & $63,629(1)$ \\
\hline
\end{tabular}


Table 4 Subgroup data for each weight estimation system (Continued)

\begin{tabular}{|c|c|c|c|c|c|c|c|c|c|}
\hline & System & Subgroup & & $\begin{array}{l}\text { Mean } \\
\text { percentage } \\
\text { error }\end{array}$ & $\begin{array}{l}\text { Lower limit } \\
\text { of } \\
\text { agreement }\end{array}$ & $\begin{array}{l}\text { Upper limit } \\
\text { of } \\
\text { agreement }\end{array}$ & $\begin{array}{l}\text { Number of children } \\
\text { (number of studies) }\end{array}$ & PW10 & $\begin{array}{l}\text { Number of children } \\
\text { (number of studies) }\end{array}$ \\
\hline & Shann formula & Age 1-5 & $\begin{array}{l}\mathrm{FE} \\
\mathrm{RE}\end{array}$ & $\begin{array}{l}-2.7 \\
-2.1\end{array}$ & $\begin{array}{l}-28.1 \\
-31.0\end{array}$ & $\begin{array}{l}22.7 \\
26.8\end{array}$ & $41,221(2)$ & $\begin{array}{l}55.1 \\
53.0\end{array}$ & $41,221(2)$ \\
\hline & & Age 6-10 & $\begin{array}{l}\text { FE } \\
\text { RE }\end{array}$ & $\begin{array}{l}-12.4 \\
-11.8\end{array}$ & $\begin{array}{l}-46.2 \\
-50.5\end{array}$ & $\begin{array}{l}21.4 \\
26.9\end{array}$ & $64,268(2)$ & $\begin{array}{l}34.8 \\
35.0\end{array}$ & $64,268(2)$ \\
\hline & Theron formula & Age 1-5 & & 8.2 & -27.1 & 43.5 & $609(1)$ & 36.8 & $609(1)$ \\
\hline & & Age 6-10 & & 30.7 & -12.6 & 74.0 & $639(1)$ & 13.5 & $639(1)$ \\
\hline \multirow{15}{*}{$\begin{array}{l}\text { Dual length- and } \\
\text { habitus based } \\
\text { methods }\end{array}$} & $\begin{array}{l}\text { Devised weight } \\
\text { estimating }\end{array}$ & $<10$ kg & $\begin{array}{l}\mathrm{FE} \\
\mathrm{RE}\end{array}$ & $\begin{array}{l}4.0 \\
3.7\end{array}$ & $\begin{array}{l}-21.9 \\
-21.5\end{array}$ & $\begin{array}{l}29.9 \\
28.9\end{array}$ & $221(2)$ & $\begin{array}{l}52.7 \\
52.5\end{array}$ & $221(2)$ \\
\hline & & $10-25$ kg & $\begin{array}{l}\mathrm{FE} \\
\mathrm{RE}\end{array}$ & $\begin{array}{l}1.2 \\
1.3\end{array}$ & $\begin{array}{l}-17.7 \\
-17.8\end{array}$ & $\begin{array}{l}20.1 \\
20.3\end{array}$ & $232(2)$ & $\begin{array}{l}70.2 \\
69.6\end{array}$ & $232(2)$ \\
\hline & & $>25$ kg & $\begin{array}{l}\mathrm{FE} \\
\mathrm{RE}\end{array}$ & $\begin{array}{l}-4.9 \\
-4.4\end{array}$ & $\begin{array}{l}-31.9 \\
-30.5\end{array}$ & $\begin{array}{l}22.2 \\
21.7\end{array}$ & $332(2)$ & $\begin{array}{l}54.0 \\
53.5\end{array}$ & $431(2)$ \\
\hline & PAWPER tape & $<10$ kg & $\begin{array}{l}\text { FE } \\
\text { RE }\end{array}$ & $\begin{array}{l}3.3 \\
2.7\end{array}$ & $\begin{array}{l}-13.8 \\
-10.7\end{array}$ & $\begin{array}{l}20.4 \\
16.1\end{array}$ & $765(4)$ & $\begin{array}{l}75.6 \\
71.6\end{array}$ & $783(5)$ \\
\hline & & $10-25 \mathrm{~kg}$ & $\begin{array}{l}\mathrm{FE} \\
\mathrm{RE}\end{array}$ & $\begin{array}{l}-0.2 \\
0.5\end{array}$ & $\begin{array}{l}-13.7 \\
-11.2\end{array}$ & $\begin{array}{l}13.2 \\
12.2\end{array}$ & $1022(4)$ & $\begin{array}{l}86.2 \\
85.5\end{array}$ & $1010(4)$ \\
\hline & & $>25$ kg & $\begin{array}{l}\mathrm{FE} \\
\mathrm{RE}\end{array}$ & $\begin{array}{l}-2.4 \\
-0.5\end{array}$ & $\begin{array}{l}-21.7 \\
-17.0\end{array}$ & $\begin{array}{l}16.9 \\
16.0\end{array}$ & $996(4)$ & $\begin{array}{l}77.1 \\
76.8\end{array}$ & $1070(5)$ \\
\hline & Mercy Method & $<10$ kg & $\begin{array}{l}\mathrm{FE} \\
\mathrm{RE}\end{array}$ & $\begin{array}{l}-1.3 \\
-3.8\end{array}$ & $\begin{array}{l}-25.1 \\
-25.3\end{array}$ & $\begin{array}{l}22.6 \\
17.7\end{array}$ & $103(2)$ & $\begin{array}{l}62.9 \\
60.0\end{array}$ & $121(3)$ \\
\hline & & $10-25$ kg & $\begin{array}{l}\mathrm{FE} \\
\mathrm{RE}\end{array}$ & $\begin{array}{l}-3.9 \\
-4.4\end{array}$ & $\begin{array}{l}-20.4 \\
-20.0\end{array}$ & $\begin{array}{l}12.6 \\
11.2\end{array}$ & $218(2)$ & $\begin{array}{l}74.3 \\
73.0\end{array}$ & 296 (3) \\
\hline & & $>25$ kg & $\begin{array}{l}\mathrm{FE} \\
\mathrm{RE}\end{array}$ & $\begin{array}{l}-4.9 \\
-4.3\end{array}$ & $\begin{array}{l}-19.7 \\
-18.2\end{array}$ & $\begin{array}{l}9.9 \\
9.6\end{array}$ & $311(2)$ & $\begin{array}{l}71.1 \\
73.4\end{array}$ & $414(3)$ \\
\hline & Wozniak method & $<10 \mathrm{~kg}$ & $\begin{array}{l}\mathrm{FE} \\
\mathrm{RE}\end{array}$ & $\begin{array}{l}-21.7 \\
-23.7\end{array}$ & $\begin{array}{l}-63.7 \\
-62.4\end{array}$ & $\begin{array}{l}20.3 \\
15.0\end{array}$ & $103(2)$ & $\begin{array}{l}29.1 \\
23.5\end{array}$ & $103(2)$ \\
\hline & & $10-25 \mathrm{~kg}$ & $\begin{array}{l}\mathrm{FE} \\
\mathrm{RE}\end{array}$ & $\begin{array}{l}0.8 \\
0.8\end{array}$ & $\begin{array}{l}-31.9 \\
-31.6\end{array}$ & $\begin{array}{l}33.5 \\
33.1\end{array}$ & $218(2)$ & $\begin{array}{l}69.5 \\
68.0\end{array}$ & $218(2)$ \\
\hline & & $>25$ kg & $\begin{array}{l}\mathrm{FE} \\
\mathrm{RE}\end{array}$ & $\begin{array}{l}-1.3 \\
-0.7\end{array}$ & $\begin{array}{l}-19.8 \\
-17.6\end{array}$ & $\begin{array}{l}17.2 \\
16.2\end{array}$ & $311(2)$ & $\begin{array}{l}78.8 \\
81.3\end{array}$ & $311(2)$ \\
\hline & Broselow tape & $<10$ kg & $\begin{array}{l}\text { FE } \\
\text { RE }\end{array}$ & $\begin{array}{l}-4.4 \\
-1.2\end{array}$ & $\begin{array}{l}-29.3 \\
-19.7\end{array}$ & $\begin{array}{l}20.5 \\
17.4\end{array}$ & 26,327 (13) & $\begin{array}{l}55.2 \\
53.0\end{array}$ & 27,345 (19) \\
\hline & & $10-25$ kg & $\begin{array}{l}\text { FE } \\
\text { RE }\end{array}$ & $\begin{array}{l}-3.8 \\
-1.3\end{array}$ & $\begin{array}{l}-22.8 \\
-18.9\end{array}$ & $\begin{array}{l}15.1 \\
16.3\end{array}$ & $51,915(15)$ & $\begin{array}{l}66.4 \\
60.7\end{array}$ & $57,102(19)$ \\
\hline & & $>25$ kg & $\begin{array}{l}\text { FE } \\
\text { RE }\end{array}$ & $\begin{array}{l}-5.3 \\
-2.8\end{array}$ & $\begin{array}{l}-29.2 \\
-23.9\end{array}$ & $\begin{array}{l}18.6 \\
18.2\end{array}$ & 72,803 (14) & $\begin{array}{l}59.7 \\
49.9\end{array}$ & $97,639(22)$ \\
\hline \multirow[t]{2}{*}{ Other } & MAC formula & Age 1-5 & $\begin{array}{l}\mathrm{FE} \\
\mathrm{RE}\end{array}$ & $\begin{array}{l}23.1 \\
21.3\end{array}$ & $\begin{array}{l}-8.3 \\
-9.0\end{array}$ & $\begin{array}{l}54.4 \\
51.5\end{array}$ & $1618(2)$ & $\begin{array}{l}17.2 \\
20.1\end{array}$ & $1618(2)$ \\
\hline & & Age 6-10 & $\begin{array}{l}\mathrm{FE} \\
\mathrm{RE}\end{array}$ & $\begin{array}{l}0.1 \\
0.0\end{array}$ & $\begin{array}{l}-39.8 \\
-37.3\end{array}$ & $\begin{array}{l}40.0 \\
37.4\end{array}$ & $1882(2)$ & $\begin{array}{l}55.5 \\
55.4\end{array}$ & $1882(2)$ \\
\hline
\end{tabular}

The outcome data for the pooled data (not separated into high-income and low- and middle-income populations) is shown with both random effects (RE) and fixed effects (FE) results

\section{Length-based weight estimation}

Every length-based system performed better than every age-based system in this study. This supports the argument that length-based weight estimation is more biologically valid than age-based estimation [10]. No length-based system achieved the acceptable outcome benchmark, however.

The two length-based formulas were originally designed to predict ideal body weight in children, but they have been used, albeit incorrectly, to estimate total body weight. The addition of a habitus-modification to these formulas has been shown to increase their performance significantly, to the same level of accuracy as the other two-dimensional systems [11]. The use of these formulas in this way shows potential, especially if used with a mobile phone app, and requires further investigation.

Although there are at least seven length-only weightestimation tapes, only the Broselow tape has been 


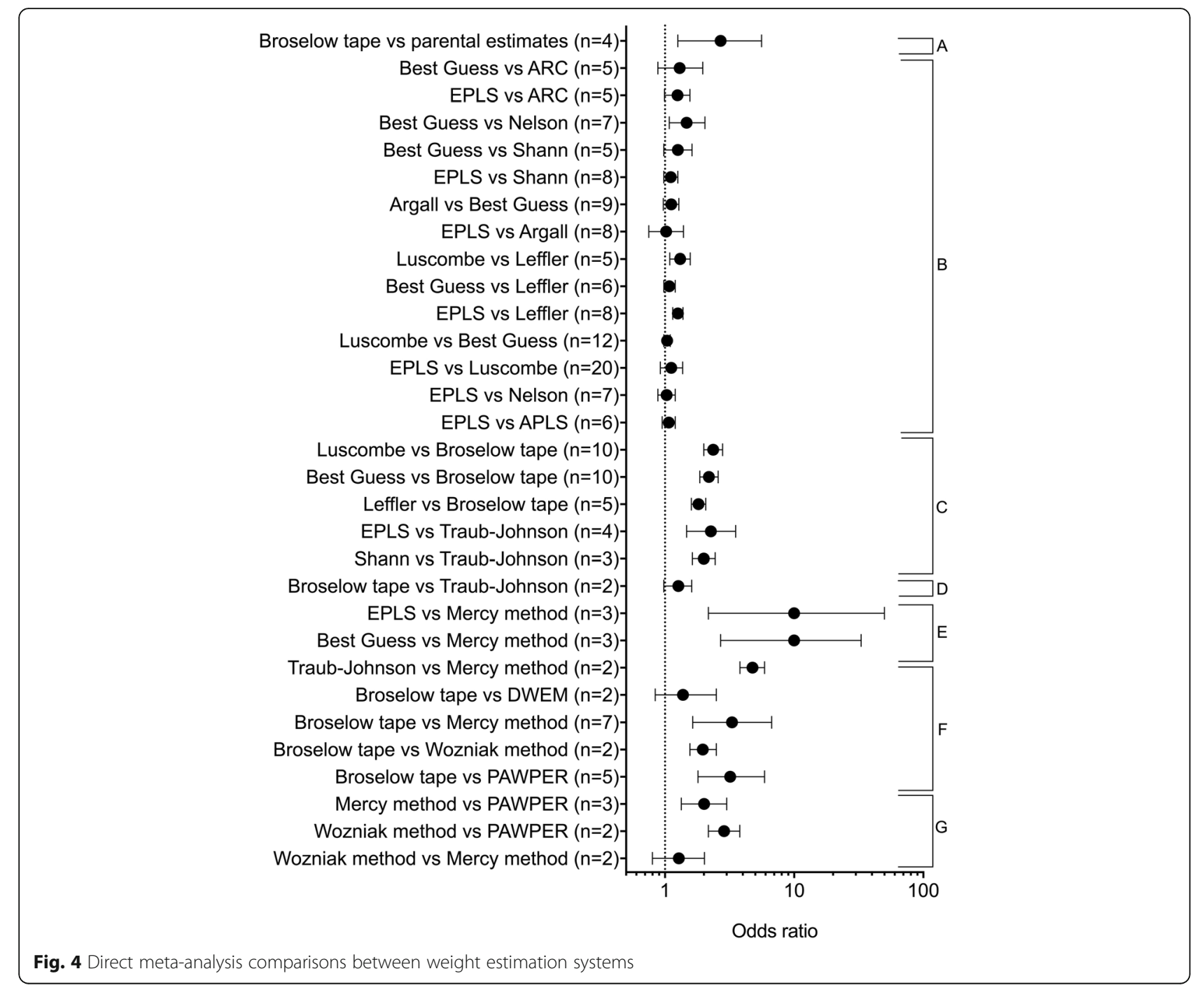

extensively studied, while the Blantyre tape, the Sandell tape and the Handtevy tape have been evaluated only in single, small studies [53-55]. The Broselow tape, like other one-dimensional length-based systems, is vulnerable to error based on individual variations of weight-forlength (differences in body habitus) [56-59]. Some authors have questioned whether the tape is still valid given the increase in prevalence of overweight and obese children and may result in the "under-resuscitation of children" [33]. Although the manufacturer recommends modifying weight estimation up a colour zone in overweight children, to reduce this underestimation of weight, this has never been formally studied and still needs to be verified $[60,61]$. However, while studies in high-income countries have demonstrated an overall underestimation of weight, studies in low- and middle-income countries have mostly shown an overestimation of weight, potentially to a dangerous degree in some populations (if drug doses were to be computed from those weights) [56, 57, 62]. Since length-based weight estimation is advocated by major, international advanced life support organisations and, since these systems are insufficiently accurate, this recommendation needs to be reconsidered and researched further $[43,63]$.

\section{Two-dimensional (dual length- and habitus-based) weight estimation}

The two-dimensional systems were far superior in accuracy to the one-dimensional age- and length-based systems. The accuracies of the Mercy method and the PAWPER tape in the meta-analysis were excellent, each with a PW10 of above $70 \%$ in both over- and undernourished populations. This finding was confirmed in individual studies, with no study reporting a onedimensional system to be more accurate than a twodimensional method. The direct meta-analysis comparisons showed that the PAWPER and Mercy 
methods were significantly more accurate than the other systems, with the PAWPER tape outperforming the Mercy method in the two studies in which they were both evaluated.

All weight estimation systems have limitations, however. The Mercy method, like all other weight estimation systems was vulnerable to human factor errors in undertrained users [64]. It also has shown considerable variation in accuracy between individual assessors [19]. The functioning of the Mercy system in emergencies still needs to be evaluated- this is of concern as one of the poorest performances of the Mercy method was in a study which measured children in the supine position, as it might be used in an emergency $[4,20]$. The PAWPER system was shown to be very accurate in two South African studies, one Australian study and one study based on NHANES data from the USA [5, 20-22, 31]. It was somewhat less accurate in two American studies with very obese populations, mostly because of difficulties in assessing body habitus, however [13, 65]. Although the tape's length-based measurements are objective and simple to perform, assessment of body habitus is more subjective and dependent on training and experience [66]. This will need to be researched further to explore more standardised and objective ways of assessing habitus.

The Devised Weight Estimating Method (DWEM), the Yamamoto obesity icon system, the Wozniak system and habitus-modified Traub-Johnson and Traub-Kichen formulas have all been shown to be significantly more accurate than length-based methods, but have not yet been sufficiently studied [11, 12, 14, 67].

\section{Estimates of weight by parents}

The utility of parental estimates of their child's weight is dependent on the parent being willing to offer a weight estimate and being accessible to healthcare personnel at the time of the child's need for emergency care [26]. The accuracy of prediction is determined by whether the accompanying parent is the regular caregiver of the child and whether or not the child has had a recent measurement of weight by the parent or in the parent's presence [9]. A previous systematic review has suggested that parental estimates are the most accurate method for obtaining a weight, when it cannot be measured [9]. In this meta-analysis, parental estimates were statistically superior to the Broselow tape on direct comparison, but there were no paired data from which direct comparisons could be made with the two-dimensional systems. Only one previous study has compared the Mercy method with parental estimates, in which parental estimates were found to be more accurate [68]. This will require further research to clarify, especially the accuracy of parental estimates in populations of different socioeconomic status and the frequency of availability of parental estimates. Since parents might not always be available, especially in the prehospital environment, it would be prudent to always have an alternative method of estimation available.

\section{Differences in weight estimation accuracy between different populations}

This study showed a clear disparity in how the onedimensional weight estimation systems performed in different populations. These differences were primarily as a result of differences in bias, however, while the underlying lack of precision within each population was similar. Thus, the variability between populations was similar to the within-population variability shown in even the most homogeneous populations. The significance of this is that, although recalibration of a system for a specific population might reduce the bias, the underlying variability and imprecision would not allow an acceptable degree of overall accuracy to be achieved. This was well shown in the study by Asskaryar et al. which failed to recalibrate the Broselow tape in an Indian population by manipulating the bias only [57]. The two-dimensional systems, with their enhanced methodology which accounts for habitus, have proven to be the closer to a universally applicable system by achieving a more uniform accuracy, both within and between populations.

\section{Limitations}

The limitations of this study are similar to what is expected from any meta-analysis of this nature [24]. The lack of data comparing parental estimates and the newer two-dimensional systems limited the comparisons between these systems. The under-reporting on subgroups of weight status also limited the ability to analyse the performance of weight estimation systems in children with habitus that deviated from the average-this would provide insight into how the systems might function in populations with a high prevalence of underweight or obese children (or both).

\section{Conclusions}

No evidence exists of an acceptable benchmark for weight estimation systems. An accuracy of at least PW10 > 70\% and PW20 > 95\% could be considered as a reference standard, since the length-based, habitusmodified systems have proven that this target is achievable across a wide range of populations.

The only weight-estimation systems that were found to be of acceptable accuracy were the two-dimensional length- and habitus-based systems. The PAWPER tape and the Mercy Method achieved an accuracy that surpassed all other methods. Wide discrepancies in the accuracy of the Broselow tape in different age groups and 
different populations raise questions about its use. It may dangerously overestimate weight in children from low- and middle-income countries or poor communities. Without exception, the age-based formulas evaluated proved to be highly inaccurate, with a possibility for patient harm, especially in low- and middle-income countries. There is sufficient evidence to conclude that the use of age-based formulas should be discouraged.

\section{Recommendations}

Dual length- and habitus-based (two-dimensional) systems should be used for weight estimation in children because of superior accuracy to other systems (high quality evidence).

The Broselow tape or parental estimates of weight should be used for weight estimation in preference to age-based formulas and healthcare provider guesses (medium quality evidence).

Age-based formulas and healthcare provider guesses should not be used for weight estimation in children because of potential patient harm (high quality evidence).

Parental estimates should be used to estimate weight in preference to length-based and age-based systems (high quality evidence). There was insufficient evidence to provide a recommendation between the two-dimensional systems and parental estimates of weight.

\section{Additional file}

Additional file 1: Table S1. Data from each study included in the meta-analysis, including subgroup data where available. (DOCX 145 kb)

Additional file 2: Figure S1. (JPEG $3645 \mathrm{~kb}$ )

\section{Abbreviations}

APLS: Advanced Paediatric Life Support formula; ARC: Australian

Resuscitation Council formula; BG: Best Guess formula; BMI: Body mass index $\left(\mathrm{kg} / \mathrm{m}^{2}\right)$; BT: Broselow tape; CAWR: Chinese age-weight rule formula; DWEM: Devised weight-estimating method; EPLS: European Paediatric Life support formula; FE: Fixed effects; LOA: 95\% limits of agreement; MAC: Midarm circumference; MPE: Mean percentage error; NCHS: National Centre for Health Statistics; OR: Odds ratio; PW10: Percentage of estimates within 10\% of actual weight; PW20: Percentage of estimates within $20 \%$ of actual weight; RE: Random effects; RMSPE: Root mean squared percentage error (\%); TJ: Traub-Johnson formula; TK: Traub-Kichen formula

\section{Funding}

No external funding for this manuscript.

\section{Financial disclosure}

MW is the developer of the PAWPER tape, but derives no financial or commercial benefit from it. $L G$ and $A B$ have no financial relationships relevant to this article to disclose.

\section{Authors' contributions}

MW conceptualised and designed the study, carried out the initial data collection, analysed the data, drafted the initial manuscript and approved the final manuscript as submitted. LG carried out the initial data collection, drafted revisions of the manuscript and approved the final manuscript as submitted. $A B$ assisted with preparation of the manuscript and approved the final manuscript as submitted. All authors agree to be accountable for all aspects of the work in ensuring that questions related to the accuracy or integrity of any part of the work are appropriately investigated and resolved.

\section{Competing interests}

MW is the developer of the PAWPER tape. LG and AB have no potential conflicts of interest to disclose.

\section{Publisher's Note}

Springer Nature remains neutral with regard to jurisdictional claims in published maps and institutional affiliations.

Received: 28 June 2017 Accepted: 7 September 2017

Published online: 21 September 2017

\section{References}

1. Luscombe $M$, Owens B. Weight estimation in resuscitation: is the current formula still valid? Arch Dis Child. 2007:92(5):412-5.

2. Meguerdichian MJ, Clapper TC. The Broselow tape as an effective medication dosing instrument: a review of the literature. J Pediatr Nurs. 2012:27(4):416-20.

3. Luten R, Zaritsky A. The sophistication of simplicity... optimizing emergency dosing. Acad Emerg Med. 2008;15(5):461-5.

4. Abdel-Rahman SM, Ridge A, Kearns GL. Estimation of body weight in children in the absence of scales: a necessary measurement to insure accurate drug dosing. Arch Dis Child. 2014;99(6):570-4.

5. Wells M, Coovadia A, Kramer E, Goldstein L. The PAWPER tape: a new concept tape-based device that increases the accuracy of weight estimation in children through the inclusion of a modifier based on body habitus. Resuscitation. 2013;84(2):227-32.

6. Hoyle JD, Davis AT, Putman KK, Trytko JA, Fales WD. Medication dosing errors in pediatric patients treated by emergency medical services. Prehospital Emergency Care. 2012;16(1):59-66.

7. Lammers R, Willoughby-Byrwa M, Fales W. Medication errors in prehospital management of simulated pediatric anaphylaxis. Prehospital Emergency Care. 2014:18(2):295-304.

8. Stevens AD, Hernandez C, Jones S, Moreira ME, Blumen JR, Hopkins E, et al. Color-coded prefilled medication syringes decrease time to delivery and dosing errors in simulated prehospital pediatric resuscitations: a randomized crossover trial. Resuscitation. 2015;96:85-91.

9. Young KD, Korotzer NC. Weight estimation methods in children: a systematic review. Ann Emerg Med. 2016;68(4):441-51. e10

10. Goldman J, Ojoo A, Abdel-Rahman S. Challenges in pediatric oral dosing. In: MacLeod S, Hill S, Koren G, Rane A, editors. Optimizing treatment for children in the developing world. Cham: Springer International Publishing; 2015. p. 33-44.

11. Wells $\mathrm{M}$, Goldstein L, Bentley $\mathrm{A}$. It is time to abandon age-based emergency weight estimation in children! A failed validation of 20 different age-based formulas. Resuscitation. 2017:116(7):73-83.

12. Yamamoto LG, Inaba AS, Young LL, Anderson KM. Improving length-based weight estimates by adding a body habitus (obesity) icon. Am J Emerg Med. 2009;27(7):810-5

13. Chavez H, Peterson R, Lo K, Arel M. Weight estimation in an inner city Pediatric Emergency Department: the effect of obesity. Am J Emerg Med. 2015;33(10):1364-7.

14. Whitfield KC, Wozniak R, Pradinuk M, Karakochuk CD, Anabwani G, Daly Z, et al. Anthropometric measures are simple and accurate paediatric weightprediction proxies in resource-poor settings with a high HIV prevalence. Arch Dis Child. 2017;102(1):10-6.

15. Abdel-Rahman SM, Ridge AL. An improved pediatric weight estimation strategy. Open Medical Devices Journal. 2012;4:87-97.

16. Jung JY, Kwak YH, Kim DK, Suh D, Chang I, Yoon C, et al. An assessment of the accuracy of a novel weight estimation device for children. Emerg Med J. 2017:34(3):163-169.

17. Tanner D, Negaard A, Huang R, Evans N, Hennes $H$. A prospective evaluation of the accuracy of weight estimation using the Broselow Tape in overweight and obese pediatric patients in the Emergency Department. Pediatr Emerg Care. 2016. doi:10.1097/PEC.0000000000000894. [Epub ahead of print].

18. Abdel-Rahman SM, Paul IM, James LP, Lewandowski A. Evaluation of the Mercy TAPE: performance against the standard for pediatric weight estimation. Ann Emerg Med. 2013;62(4):332-339.e6. 
19. Abdel-Rahman SM, Ahlers N, Holmes A, Wright K, Harris A, Weigel J, et al. Validation of an improved pediatric weight estimation strategy. J Pediatr Pharmacol Ther. 2013;18(2):112-21.

20. Wells M, Goldstein L, Bentley A. A validation study of the PAWPER XL tape: accurate estimation of both total and ideal body weight in children up to 16 years of age. Trauma and Emergency Care. 2017;2(4):1-8.

21. Georgoulas V, Wells M. The PAWPER tape and the Mercy Method outperform other methods of weight estimation in children in South Africa. S Afr Med J. 2016;106(9):933-9.

22. O'Leary F, John-Denny B, McGarvey K, Hann A, Pegiazoglou I, Peat J. Estimating the weight of ethnically diverse children attending an Australian emergency department: a prospective, blinded, comparison of age-based and length-based tools including Mercy, PAWPER and Broselow. Arch Dis Child. 2017;102(1):46-52

23. Wells M, Goldstein L, Bentley A. A systematic review and meta-analysis of the accuracy of weight estimation systems used in paediatric emergency care in developing countries. African Journal of Emergency Medicine. 2017; In Press

24. Williamson PR, Lancaster GA, Craig JV, Smyth RL. Meta-analysis of method comparison studies. Stat Med. 2002;21(14):2013-25.

25. Berman NG, Parker RA. Meta-analysis: neither quick nor easy. BMC Med Res Methodol. 2002;2:10

26. Kelly A. Estimation of children's weight in medical emergencies. In: Preedy $V$, editor. Handbook of anthropometry: physical measures of human form in health and disease. New York: Springer-Verlag; 2012. p. 1151-61

27. Marlow R, Lo D, Walton L. Accurate paediatric weight estimation by age: mission impossible? Arch Dis Child. 2011;96(Suppl 1):A1-2.

28. Park J, Kwak YH, Kim do K, Jung JY, Lee JH, Jang HY, et al. A new agebased formula for estimating weight of Korean children. Resuscitation. 2012;83(9):1129-34.

29. Ralston ME, Myatt MA. Weight estimation tool for children aged 6 to 59 months in limited-resource settings. PLoS One. 2016;11(8):e0159260.

30. Stewart D. Accuracy of the Broselow tape for estimating paediatric weight in two Australian Emergency Departments: University of Sydney; 2009.

31. Wells M, Goldstein L, Bentley A. Development and validation of a method to estimate bodyweight in critically ill children using length and mid-arm circumference measurements - the PAWPER XL-MAC system. S Afr Med J. 2017; In Press

32. Hashikawa A, Juhn Y, Homme J, Gardner B, Moore B. Does length-based resuscitation tape accurately place pediatric patients into appropriate colorcoded zones? Pediatr Emerg Care. 2007;23(12):856-61.

33. Milne KW, Yasin A, Knight J, Noel D, Lubell R, Filler G. Ontario children have outgrown the broselow tape. Canadian Journal of Emergency Medicine. 2012;14(1):25-30.

34. Thompson MT, Reading MJ, Acworth JP. Best Guess method for age-based weight estimation in paediatric emergencies validation and comparison with current methods. Emergency Medicine Australasia. 2007;19:535-42.

35. Williams B, Boyle M, O'Meara P. Can undergraduate paramedic and nursing students accurately estimate patient age and weight? Prehospital and Disaster Medicine. 2010;25(2):171-7.

36. Greig A, Ryan J, Glucksman E. How good are doctors at estimating children's weight? J Accid Emerg Med. 1997;14:101-3.

37. Nieman CT, Manacci CF, Super DM, Mancuso C, Fallon WF Jr. Use of the Broselow tape may result in the underresuscitation of children. Acad Emerg Med. 2006;13(10):1011-9.

38. Rosenberg M, Greenberger S, Rawal A, Latimer-Pierson J, Thundiyil J. Comparison of Broselow tape measurements versus physician estimations of pediatric weights. Am J Emerg Med. 2011;29(5):482-8.

39. Lim CAE, Kaufman BJ, O'Connor J Jr, Cunningham SJ. Accuracy of weight estimates in pediatric patients by prehospital Emergency Medical Services personnel. Am J Emerg Med. 2013;31(7):1108-12.

40. Nash DB. Meet the enemy: he is us. Am J Med Qual. 2011;26(1 Suppl):4S.

41. Luten R. Error and time delay in pediatric trauma resuscitation: Addressing the problem with color-coded resuscitation aids. Surg Clin N Am. 2002; 82(2):303-14.

42. Winship C, Williams B, Boyle M. Which paediatric weight formula is best suited for the out-of-hospital field? Journal of Paramedic Practice. 2012;4(9):533-41.

43. Advanced Life Support Group. Advanced Paediatric Life Support: The Practical Approach (APLS). 5th ed. New York: BMJ Books - Publisher: John Wiley \& Sons (Wiley-Blackwell); 2011.
44. Young TP, Chen BG, Kim TY, Thorp AW, Brown L. Finger counting: an alternative method for estimating pediatric weights. Am J Emerg Med. 2014;32(3):243-247.

45. Cattermole GN, Leung MP, So HK, Mak PS, Graham CA, Rainer TH. Agebased formulae to estimate children's weight in the emergency department. Emerg Med J. 2011;28(5):390-6.

46. Flannigan C, Bourke TW, Sproule A, Stevenson M, Terris M. Are APLS formulae for estimating weight appropriate for use in children admitted to PICU? Resuscitation. 2014;85(7):927-31.

47. Britnell S, Koziol-McLain J. Weight estimation in paediatric resuscitation: a hefty issue in New Zealand. Emergency Medicine Australasia. 2015;27(3):251-6.

48. Pollock L, Molyneux E, Jefferis O, Bunn J. Estimating children's weights: a developing country perspective. Arch Dis Child. 2007:92(10):938-9.

49. Batmanabane G, Kumar Jena P, Dikshit R, Abdel-Rahman SM. Using the Mercy method for weight estimation in Indian children. Global Pediatric Health. 2015; January-December:1-7.

50. Dicko A, Alhousseini ML, Sidibé B, Traoré M, Abdel-Rahman SM. Evaluation of the Mercy weight estimation method in Ouelessebougou, Mali. BMC Public Health. 2014;14:270.

51. Britnell S, Taylor S, Koziol-McLain J. Emergency weight estimation lookup tables for New Zealand children aged 5-10 years. Emergency Medicine Australasia. 2016;28(5):558-63.

52. Black K, Barnett $P$, Wolfe $R$, Young $S$. Are methods used to estimate weight in children accurate? Emerg Med. 2002;14(2):160-5.

53. Molyneux E, Brogan R, Mitchell G, Gove S. Children's weights: guess or measure by tape. Lancet. 1999;354:1616.

54. Allison N, Norton I. Emergency weight estimation in Aboriginal and Torres Strait Islander children in the Northern Territory: are the current methods accurate? Emergency Medicine Australasia. 2014;26(5):487-93.

55. Lowe CG, Campwala RT, Ziv N, Wang VJ. The Broselow and Handtevy Resuscitation Tapes: a comparison of the performance of pediatric weight prediction. Prehospital and Disaster Medicine. 2016:31(4):364-75.

56. Ramarajan N, Krishnamoorthi R, Strehlow M, Quinn J, Mahadevan SV. Internationalizing the Broselow tape: how reliable is weight estimation in Indian children. Acad Emerg Med. 2008;15(5):431-6.

57. Asskaryar F, Shankar R. An Indian pediatric emergency weight estimation tool: prospective adjustment of the Broselow tape. Int J Emerg Med. 2015:8(1):78.

58. Wells $M$, Goldstein L, Bentley A. Accuracy of weight estimation by the Broselow tape is substantially improved by including a visual assessment of body habitus. Pediatric Research. 2017. In Press. doi:10.1038/pr.2017.222

59. Clark M, Ogunnyi A, Lewis R, Patel D. Is the Broselow tape valid in South Sudan, "the hungriest place on earth"? Ann Emerg Med. 2013;62(4):S98.

60. Broselow ${ }^{\oplus}$ Pediatric Emergency Tape 2011 [Acessed 25 Sept 2015, 2015] Available from: https://www.armstrongmedical.com/index.cfm/go/product. detail/sec/3/ssec/14/fam/2371.

61. Deboer S, Seaver M, Broselow J. Color coding to reduce errors. Am J Nurs 2005:105(8):68-71.

62. Clark MC, Lewis RJ, Fleischman RJ, Ogunniyi AA, Patel DS, Donaldson RI. Accuracy of the Broselow Tape in South Sudan, "The Hungriest Place on Earth". Acad Emerg Med. 2016;23(1):21-8.

63. Kleinman ME, Chameides L, Schexnayder SM, Samson RA, Hazinski MF, Atkins DL, et al. Pediatric advanced life support: 2010 American Heart Association guidelines for cardiopulmonary resuscitation and emergency cardiovascular care. Pediatrics. 2010;126(5):e1361-99.

64. Abdel-Rahman A, Jacobsen R, Watts J, Doyle S, O'Malley D, Hefner T, et al. Comparative performance of pediatric weight estimation techniques: a human factor errors analysis. Pediatr Emerg Care. 2015;00:00.

65. Garcia CM, Meltzer JA, Chan KN, Cunningham SJ. A validation study of the PAWPER (Pediatric Advanced Weight Prediction in the Emergency Room) tape-a new weight estimation tool. J Pediatr. 2015;167(1):173-177.e1.

66. Goldstein L, Wells M. Fat is the new normal. J Pediatr. 2016;168:257.

67. Garland JS, Kishaba RG, Nelson DB, Losek JD, Sobocinski KA. A rapid and accurate method of estimating body weight. Am J Emerg Med. 1986:4(5):390-3.

68. Samerchua A, Suraseranivongse S, Komoltri C. A Comparison of pediatric weight estimation methods for emergency resuscitation. Pediatr Emerg Care. 2017. doi:10.1097/PEC.0000000000001137. [Epub ahead of print].

69. Traub SL, Kichen L. Estimating ideal body mass in children. Am J Hosp Pharm. 1983;40(1):107-10. 
70. Lubitz DS, Seidel JS, Chameides L, Luten RC, Zaritsky AL, Campbell FW. A rapid method for estimating weight and resuscitation drug dosages from length in the pediatric age group. Ann Emerg Med. 1988;17(6):576-81.

71. Oakley P. Inaccuracy and delay in decision making in paediatric resuscitation and a proposed reference chart to reduce error. Br Med J. 1988;297:817-9.

72. Losek JD, Garland J, Nelson DB. Body habitus + height = accurate weight estimate. Ann Emerg Med. 1989;18(6):709.

73. Haftel AJ, Khan N, Lev R, Schonfeld N. Hanging leg weight-a rapid technique for estimating total body weight in pediatric resuscitation. Ann Emerg Med. 1990;19(5):523-6.

74. Hughes G, Spoudeas H, Kovar IZ, Millington HT. Tape measure to aid prescription in paediatric resuscitation. Archives of Emergency Medicine. 1990;7(1):21-7.

75. Leffler S, Hayes M. Analysis of parental estimates of children's weights in the ED. Ann Emerg Med. 1997;30(2):167-70.

76. Dearlove CB, Dearlove O. Visual estimation of children's weights. Anaesthesia. 1999;54(12):1228-9.

77. Goldman RD, Buskin S, Augarten A. Parental estimates of their child's weight: accurate for resuscitation drug doses. Pediatr Emerg Care. 1999;15(1):19-21.

78. Harris M, Patterson J, Morse J. Doctors, nurses and parents are equally poor at estimating pediatric weights. Pediatr Emerg Care. 1999;15:17-8.

79. Kun W, Cheng K, Yuen M, Tung W. How good is the Broselow tape measurement for estimation of body weights in paediatric patients for application in Hong Kong? Hong Kong Journal of Paediatrics. 2000;5(1):25-30.

80. Carroll W, Jay N, Alexander J. Towards better weight estimation in the seriously ill child - a comparison of methods. Arch Dis Child. 2001; 84(Supp I):A12.

81. Vilke GM, Marino A, Fisher R, Chan TC. Estimation of pediatric patient weight by EMT-PS. J Emerg Med. 2001;21(2):125-8.

82. Hofer CK, Ganter M, Tucci M, Klaghofer R, Zollinger A. How reliable is length-based determination of body weight and tracheal tube size in the paediatric age group? The Broselow tape reconsidered. Br J Anaesth. 2002; 88(2):283-5.

83. Uesugi T, Okada N, Sakai K, Nishina K, Mikawa K, Shiga M. Accuracy of visual estimation of body height and weight in supine paediatric patients. Paediatr Anaesth. 2002;12(6):489-94.

84. Argall JA, Wright N, Mackway-Jones K, Jackson R. A comparison of two commonly used methods of weight estimation. Arch Dis Child. 2003; 88(9):789-90.

85. Potier K. Broselow tape or APLS formula to estimate weight in children. 2006. Available from: http://bestbets.org/bets/bet.php?id=64.

86. Hohenhaus SM, Frush KS. Pediatric patient safety: common problems in the use of resuscitative aids for simplifying pediatric emergency care. J Emerg Nurs. 2004;30(1):49-51.

87. Moore B, Hankins D, Shimmin S. Use of the length-based resuscitation tape for estimating pediatric weight in the pre-hospital setting. Prehospital Emergency Care. 2004;8(1):87

88. Luscombe M. "Kid's aren't what they used to be": a study of paediatric patients' weights and their relationship to current weight estimation formulae. Br J Anaesth. 2005;95(4):578.

89. Theron L, Adams A, Jansen K, Robinson E. Emergency weight estimation in Pacific Island and Maori children who are large-for-age. Emergency Medicine Australasia. 2005;17:238-43.

90. Bavdekar SB, Sathe S, Jani P. Prediction of weight of Indian children aged up to two years based on foot-length: implications for emergency areas. Indian Pediatr. 2006:43(2):125-30.

91. Varghese A, Vasudevan VK, Lewin S, Indumathi CK, Dinakar C, Subba Rao SD. Do the length-based (Broselow ${ }^{\circledast}$ ) tape, APLS, Argall and Nelson's formulae accurately estimate weight of Indian children? Indian Pediatr. 2006;43(10):889-94.

92. Anderson M. Underestimation potentially better than overestimation. Arch Dis Child. 2007;92(10):937.

93. Dieckmann RA. The dilemma of paediatric drug dosing and equipment sizing in the era of patient safety. Emergency Medicine Australasia. 2007;19:490-3.

94. DuBois D, Baldwin S, King WD. Accuracy of weight estimation methods for children. Pediatr Emerg Care. 2007;23(4):227-30.

95. Im T, Kang B, Choi H, Won T, Yeon J. A study on the accuracy of weight estimation using the Broselow tape in Korean children. Ann Emerg Med. 2007;50(3):S40

96. Jang HY, Shin SD, Kwak YH. Can the Broselow tape be used to estimate weight and endotracheal tube size in Korean children? Acad Emerg Med. 2007;14(5):489-91.
97. Kelly AM, Kerr D, Clooney M, Krieser D, Nguyen K. External validation of the best Guess formulae for paediatric weight estimation. Emergency Medicine Australasia. 2007;19(6):543-6.

98. Krieser D, Nguyen K, Kerr D, Jolley D, Clooney M, Kelly AM. Parental weight estimation of their child's weight is more accurate than other weight estimation methods for determining children's weight in an emergency department? Emerg Med J. 2007;24(11):756-9.

99. Luten R, Kahn N, Wears R, Kissoon N. Predicting endotracheal tube size by length in newborns. J Emerg Med. 2007;32(4):343-7.

100. Nguyen K, Krieser D, Kerr D, Jolley D, Clooney M, Kelly AM. Failed validation of the Argall weight formula for estimating children's weight in an Australian Emergency Department. Acad Emerg Med. 2007;14(5):486-8.

101. Patel A, Zikos V, Rzechula K, McQuillen K. The accuracy of pediatric weight in the Emergency Department: do caregiver weight estimates measure up? Ann Emerg Med. 2007;50(3, Supplement):S123-4.

102. Tinning K, Acworth J. Make your Best Guess: an updated method for paediatric weight estimation in emergencies. Emergency Medicine Australasia. 2007;19:528-34.

103. Zikos V, Patel A, Rzechula K, K M. The accuracy of pediatric weight in the emergency department: do caregiver weight estimates measure up? Ann Emerg Med. 2007:50(3):S123-4.

104. Gardner S, Haber R. Children's weight "guesstimates": could we? Ann Emerg Med. 2008:51(4):484-5.

105. Wells M, Kramer E. Optimizing emergency drug dosing in children. Acad Emerg Med. 2008;15(12):1325.

106. Zink K, Bohn M, Hood T, Topp RV, Berger J. A comparison of methods of assessing patient body weight in the pediatric emergency department. Kentucky Nurse. 2008;56(3):12.

107. Anstett D, Bawden J, Moylette E. Does the Broselow tape accurately estimate the weight of healthy Irish children? Canadian Journal of Emergency Medicine. 2009;11:289.

108. Cattamanchi S, Banala S, RV T. Assessing competency of the BroselowLuten pediatric resuscitation tape: a prospective, cross sectional, analytical study of 15,000 Indian school children. Ann Emerg Med. 2009;54(3):S130-1.

109. Cattermole GN, Leung M, Mak P, So HK, Graham CA, Rainer TH. Children's weights correlate more strongly with mid-arm circumference (MAC) than with age, height or foot-length. J Emerg Med. 2009;37(2):228-9.

110. Partridge RL, Abramo TJ, Haggarty KA, Hearn R, Sutton $K L, A n A Q$, et al. Analysis of parental and nurse weight estimates of children in the pediatric emergency department. Pediatr Emerg Care. 2009;25(12):816-8.

111. Paw R, Majeed MA. Emergency paediatric weight estimation. Does the APLS formula hold true? J Emerg Med. 2009;37(2):231.

112. Sandell JM, Charman SC. Can age-based estimates of weight be safely used when resuscitating children? Emerg Med J. 2009;26(1):43-7.

113. So TY, Farrington E, Absher RK. Evaluation of the accuracy of different methods used to estimate weights in the pediatric population. Pediatrics. 2009;123(6):e1045-51.

114. Bicer S, Oguzhan A, Vitrinel A. Evaluation of the weight estimation formulae in childhood used frequently. Türkiye Klinikleri Pediatri Dergisi. 2010;19(3): 197-202.

115. Casey J, Borland M. Best Guess method: a further external validation study and comparison with other methods. Emergency Medicine Australasia. 2010;22(1):68-74.

116. Cattermole GN, Leung PY, Mak PS, Graham CA, Rainer TH. Mid-arm circumference can be used to estimate children's weights. Resuscitation. 2010;81(9):1105-10.

117. Lulic I, Kovic I. Comparing methods for weight estimation of children: a preliminary study. Resuscitation. 2010;81(2, Supplement):S77.

118. Rosenberg M, Thundiyil J, Greenberger S, Rawal A, Latimer-Pierson J. Does physician estimates of pediatric patient weights lead to inaccurate medication dosages. Ann Emerg Med. 2010;56(3 (Suppl September 2010):S47.

119. Bourdeau S, Copeland J, Milne WK. Accuracy of the Broselow tape in estimating the weight of First Nations children. Canadian Journal of Rural Medicine. 2011;16(4):121-5.

120. Cattermole GN, Graham CA, Rainer TH. Age-based weight prediction is imprecise. Emerg Med J. 2011;29(1):82-3.

121. Costelloe C, Montgomery AA, Redmond NM, Fletcher M, Hollinghurst S, Peters TJ, et al. Medicine dosing by weight in the home: can parents accurately weigh preschool children? A method comparison study. Arch Dis Child. 2011;96(12):1187-90 
122. Geduld H, Hodkinson PW, Wallis LA. Validation of weight estimation by age and length based methods in the Western Cape. South Africa population Emergency Medicine Journal. 2011;28(10):856-60.

123. Huybrechts I, Himes JH, Ottevaere C, De Vriendt T, De Keyzer W, Cox B, et al. Validity of parent-reported weight and height of preschool children measured at home or estimated without home measurement: a validation study. BMC Pediatr. 2011;11:63.

124. Kelly AM, Nguyen K, Krieser D. Validation of the Luscombe weight formula for estimating children's weight. Emergency Medicine Australasia. 2011; 23(1):59-62.

125. Knight JC, Nazim M, Riggs D, Channel J, Mullet C, Vaughan R, et al. Is the Broselow tape a reliable indicator for use in all pediatric trauma patients?: a look at a rural trauma center. Pediatr Emerg Care. 2011;27(6):479-82.

126. Luscombe MD, Owens BD, Burke D. Weight estimation in paediatrics: a comparison of the APLS formula and the formula 'Weight=3(age)+7'. Emerg Med J. 2011;28(7):590-3.

127. Wells M. The PAWPER tape: a more accurate form of tape-based weight estimation. Sanguine. 2011;1(2):4-6.

128. Ali K, Sammy I, Nunes P. Is the APLS formula used to calculate weight-forage applicable to a Trinidadian population? BMC Emergency Medicine. 2012;12:9.

129. Cantle F, Cattermole G, Graham C, Rainer T. Validation of the Chinese age weight rules and the mid-arm circumference method to estimate children's weight. Dublin: International Conference on Emergency Medicine; 2012.

130. Elgie LD, Williams AR. Using age on clothes size label to estimate weight in emergency paediatric patients. Eur J Emerg Med. 2012;19(5):338-40.

131. Garwood J, McEwan A. Estimating paediatric weight: a new formula. Paediatric Anaesthesia and Intensive Care. 2012;29(Suppl 50):153-4.

132. Heyming T, Bosson N, Kurobe A, Kaji AH, Gausche-Hill M. Accuracy of paramedic Broselow tape use in the prehospital setting. Prehospital Emergency Care. 2012;16(3):374-80.

133. Seddon C, Lockitt L, Dhanjal S, Eisenhut M. Validation of advanced paediatric life support formulas for weight calculation in a multiethnic population. International Scholarly Research Notices: Pediatrics. 2012; 2012:869634.

134. Sinha M, Lezine MW, Frechette A, Foster KN. Weighing the pediatric patient during trauma resuscitation and its concordance with estimated weight using Broselow Luten emergency tape. Pediatr Emerg Care. 2012;28(6):544-7.

135. Trakulsrichai $S$, Boonsri C, Chatchaipun P, Chunharas A. Accuracy of three methods used for Thai children's body weight estimation. J Med Assoc Thail. 2012;95(9):1194-9.

136. Wozniak R. The evaluation of potential weight-estimation methods in a primarily HIV positive cohort in Botswana for use in resource limited settings: The University of British Columbia; 2012.

137. Akabarian S, Vahedparast H, Ravanipour M, Mirzaei K. Comparison of Broselow tape measurements versus mother estimations of pediatric weights. Iranian South Medical Journal. 2013;16(2):138-43.

138. Cattermole GN, Leung PY, Graham CA, Rainer TH. Too tall for the tape: the weight of schoolchildren who do not fit the Broselow tape. Emerg Med J. 2013; [epub ahead of print]

139. Graves L, Chayen G, Peat J, O'Leary F. A comparison of actual to estimated weights in Australian children attending a tertiary children's hospital, using the original and updated APLS, Luscombe and Owens, Best Guess formulae and the Broselow tape. Resuscitation. 2014;85(3):392-6.

140. Hegazy $M$, Taher $E$. Validating a new formula for weight estimation in pediatric cancer patients. International Research Journal of Medicine and Medical Sciences. 2013;1(1):34-9.

141. House DR, Ngetich E, Vreeman RC, Rusyniak DE. Estimating the weight of children in Kenya: do the Broselow tape and age-based formulas measure up? Ann Emerg Med. 2013;61(1):1-8.

142. Loo PY, Chong SL, Lek N, Bautista D, Ng KC. Evaluation of three paediatric weight estimation methods in Singapore. J Paediatr Child Health. 2013; 49(4):E311-6.

143. Suh D, Kwak Y, Kim D, Jeong J. Estimating weights using the Broselow tape in Korea: comparison of old and new versions of the Broselow tape use. Ann Emerg Med. 2013;62(4):S109.

144. Ackwerh R, Lehrian L, Nafiu OO. Assessing the accuracy of common pediatric age-based weight estimation formulae. Anesth Analg. 2014; 118(5):1027-33.

145. Chiengkriwate $P$, Donnapee $R$, Geater $A$. The accuracy of the Broselow tape in the weight estimation of Thai children. Asian Biomedicine. 2014;8(6):799-807.
146. Eke C, Ubesie A, Ibe B. Comparison of actual (measured) weights and heights with the standard formula methods of estimation among children in Enugu. Nigerian Journal of Pediatrics. 2014;41:307-11.

147. Erker CG, Santamaria M, Moellmann M. Size does matter-age-related weight estimation in "tall $n$ ' thin" and "tiny $n$ ' thick" children and a new habitusadapted alternative to the EPLS-formula. Resuscitation. 2014;85(9):1174-8.

148. Omisanjo AO, Orimadegun AE, Akinbami FO. Accuracy of Nelson and best Guess formulae in estimation of weights in Nigerian children population. Annals of Ibadan Postgraduate Medicine. 2014;12(2):80-8.

149. Badeli H, Hashemian $H$, Nazari N, Rad AH. The percentage of error of different weight estimation methods toward actual weight in children admitted to 17 Shahrivar Hospital. International Journal of Preventive Medicine. 2015;6:13

150. Khouli M, Ortiz MI, Romo-Hernández G, Martínez-Licona D, Stelzner SM. Use of the Broselow tape in a Mexican Emergency Department. J Emerg Med. 2015;48(6):660-6.

151. Skrobo D, Kelleher G. CORKSCREW 2013 CORK study of children's realistic estimation of weight. Emerg Med J. 2015;32(1):32-5

152. Talib NJ, Rahm G, Abdel-Rahman SM. Estimating weight in children with Down syndrome. Global Pediatric Health. 2015;2:2333794X14568450.

153. Young TP, Washington O, Flanery A, Guptill M, Reibling ET, Brown L, et al. Comparison of the finger counting method, the Broselow tape and common weight estimation formulae in Filipino children after Typhoon Haiyan. Emergency Medicine Australasia. 2015;27(3):239-44.

154. AlHarbi TM, AlGarni A, AlGamdi F, Jawish M, Wani TA, Abu-Shaheen AK. The accuracy of Broselow Tape weight estimate among pediatric population. Biomed Res Int. 2016;2016:7042947.

155. Aliyu I, Abdulsalam M. Is the Broselow tape and APLS formula applicable to Nigerian children? The Kano experience. Tropical Journal of Medical Research. 2016;19(1):20-3.

156. Carasco CF, Fletcher P, Maconochie I. Review of commonly used age-based weight estimates for paediatric drug dosing in relation to the pharmacokinetic properties of resuscitation drugs. Br J Clin Pharmacol. 2016;81(5):849-56.

157. Chassee T, Reischmann D, Mancera M, Hoyle JD. Emergency medical dispatchers can obtain accurate pediatric weights from 9-1-1 callers. Prehospital Emergency Care. 2016;20(6):808-14.

158. Jung J, Kwon $\mathrm{H}$, Choi Y. Methods of weight estimation in pediatric resuscitation. Pediatric Emergency Medicine Journal. 2016;3(1):9-14.

159. Mishra DG, Kole T, Nagpal R, Smith JP. A correlation analysis of Broselow Pediatric Emergency Tape-determined pediatric weight with actual pediatric weight in India. World J Emerg Med. 2016;7(1):40-3.

160. Nosaka N, Fujiwara T, Knaup E, Okada A, Tsukahara H. Validity of mothers' reports of children's weight in Japan. Acta Med Okayama. 2016;70(4):255-9.

161. Sahar M, Nordin N, Nor A, Zakaria M. Weight estimation method in Emergency Department in Malaysia: is Broselow Tape (BT) reliable? Jurnal Teknologi (Sciences \& Engineering). 2016;78(6-8):113-7.

162. So J, Chow E, Cattermole G, Rainer T. A comparison of the performance of different age-based paediatric weight estimation formulae in Hong Kong children. Hong Kong Journal of Emergency Medicine. 2016;23:3-12.

163. So JL, Chow EP, Cattermole GN, Graham CA, Rainer TH. Finger counting method is more accurate than age-based weight estimation formulae in estimating the weight of Hong Kong children presenting to the emergency department. Emergency Medicine Australasia. 2016;28(6):691-7.

164. Bowen L, Zyambo M, Snell D, Kinnear J, Bould MD. Evaluation of the accuracy of common weight estimation formulae in a Zambian paediatric surgical population. Anaesthesia. 2017;72(4):470-8.

165. Reilly JJ. Mid-upper arm circumference (MUAC): new applications for an old measure. Arch Dis Child. 2017;102(1):1-2.

166. Trainarongsakul T, Sanguanwit $P$, Rojcharoenchai S, Sawanyawisuth $K$, Sittichanbuncha Y. The RAMA Ped Card: does it work for actual weight estimation in child patients at the emergency department. World J Emerg Med. 2017;8(2):126-30

167. Waseem M, Chen J, Leber M, Giambrone AE, Gerber LM. A reexamination of the accuracy of the Broselow Tape as an instrument for weight estimation. Pediatr Emerg Care. 2017. doi:10.1097/PEC.0000000000000982. [Epub ahead of print]. 